\title{
A NOVEL, ELASTICALLY-BASED, REGENERATIVE BRAKE AND LAUNCH ASSIST MECHANISM
}

\author{
Thesis \\ Submitted to \\ The School of Engineering of the \\ UNIVERSITY OF DAYTON \\ In Partial Fulfillment of the Requirements for \\ The Degree of \\ Master of Science in Mechanical Engineering \\ By \\ Joshua E. Nieman \\ UNIVERSITY OF DAYTON \\ Dayton, Ohio
}

May, 2014 


\section{A NOVEL, ELASTICALLY-BASED, REGENERATIVE BRAKE AND LAUNCH ASSIST MECHANISM}

Name: Nieman, Joshua E.

\section{APPROVED BY:}

David H. Myszka, Ph.D.

Advisor Committee Co-Chairman

Professor, Department of Mechanical and Aerospace Engineering
Andrew P. Murray, Ph.D.

Advisor Committee Co-Chairman

Professor, Department of Mechanical and Aerospace Engineering

David Perkins, Ph.D.

Committee Member

Lecturer, Department of Mechanical and

Aerospace Engineering

John G. Weber, Ph.D.

Associate Dean

School of Engineering
Tony E. Saliba, Ph.D.

Dean, School of Engineering

\& Wilke Distinguished Professor 


\section{(c) Copyright by}

Joshua E. Nieman

All rights reserved

2014 


\begin{abstract}
A NOVEL, ELASTICALLY-BASED, REGENERATIVE BRAKE AND LAUNCH ASSIST

MECHANISM

Name: Nieman, Joshua E.

University of Dayton

Advisor: Dr. David H. Myszka

This thesis project presents the development of a regenerative brake and launch assist (RBLA) mechanism that stores energy in an elastic medium. Automotive regenerative braking systems harness kinetic energy while a vehicle decelerates, and subsequently uses that stored energy to assist propulsion. Commercially available hybrid vehicles use generators, batteries, and motors to electrically implement regenerative braking and increase overall vehicle efficiency. With the intent of applying regenerative braking technology to conventional automobiles equipped having only an internal combustion engine, a spring-based mechanical device is proposed. This RBLA concept implements clutches, gears, a ratchet and a spring. The mechanism captures energy from, and releases energy to, an additional shaft allowing the axle to rotate in one direction. Governing equations were formulated and validated by a dynamic simulation. In creating the detailed design, an optimization determined ideal spring and mechanism dimensions. A physical prototype was designed and fabricated to demonstrate the concept. A model of the proposed spring-based RBLA has been found to appreciably increase the urban fuel efficiency for an average sedan.
\end{abstract}




\section{ACKNOWLEDGMENTS}

First, I want to thank my parents for supporting me through college. Amanda, my fiance for always being there with me through everything. Additionally, I would like to thank all of my advisors: Aaron Altman, who helped me so much throughout my undergrad as well as Dave Myszka and Drew Murray who helped me through my graduate school. Thank you. 


\section{TABLE OF CONTENTS}

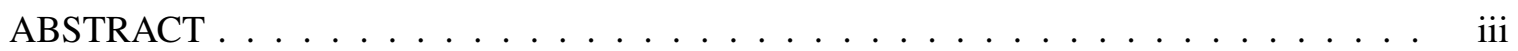

ACKNOWLEDGMENTS . ...................... iv

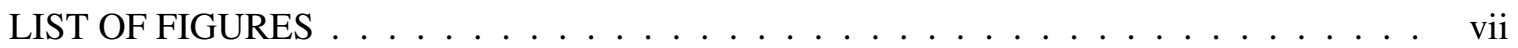

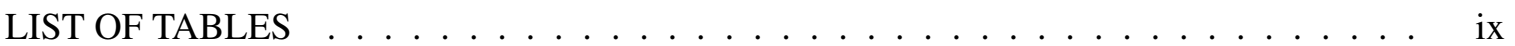

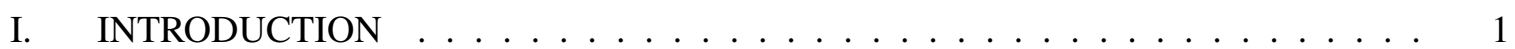

1.1 Regenerative Braking . . . . . . . . . . . . . . . . . . . . 1

1.2 Spring Based Regenerative Braking and Launch Assist System . . . . . . . . . . 5

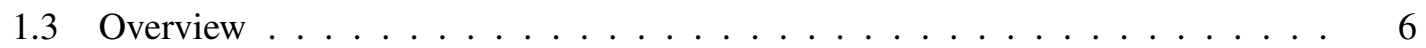

II. THE REGENERATIVE BRAKING AND LAUNCH ASSIST DEVICE . . . . . . . . 7

2.1 Description of Concept . . . . . . . . . . . . . . . . . 7

2.1.1 Concept Requirements . . . . . . . . . . . . . . . . 7

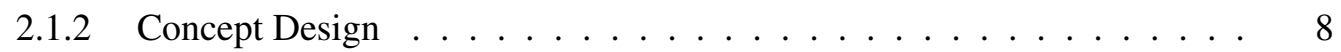

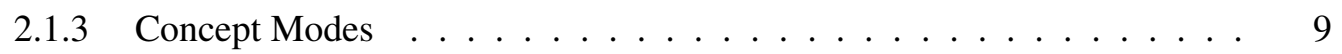

2.1 .4 Concept Controls . . . . . . . . . . . . . . . . . . . 12

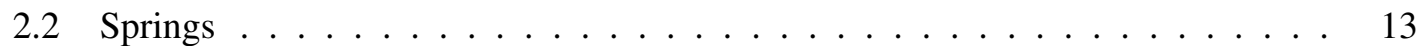

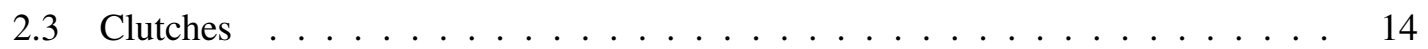

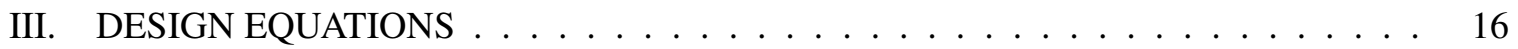

3.1 RBLA Mathematical Model . . . . . . . . . . . . . . . . . . 16

3.1.1 Equations of Motion Method . . . . . . . . . . . . . . 16

3.1 .2 Energy Method . . . . . . . . . . . . . . . . . 20

3.1.3 Extension Spring Equations . . . . . . . . . . . . . . . . 21

3.2 Justification for Negating the Drag Force . . . . . . . . . . . . . . . . 22 


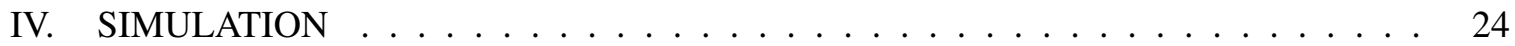

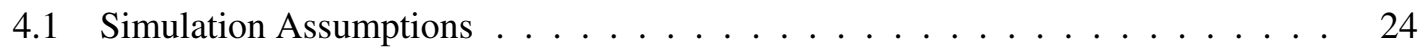

4.2 Pure Launch Assist . . . . . . . . . . . . . . . . . . . . . 25

4.3 Simulating the EPA Cycle . . . . . . . . . . . . . . 28

4.3.1 Inventor Dynamic Simulation . . . . . . . . . . . . . . . . . 29

4.3 .2 Solidworks Motion Study . . . . . . . . . . . . . . . . . 30

4.3 .3 EPA MATLAB Simulation $\ldots \ldots \ldots$

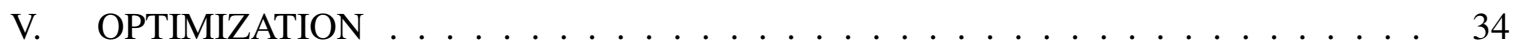

5.1 RBLA Objective Function . . . . . . . . . . . . . . . . . . 35

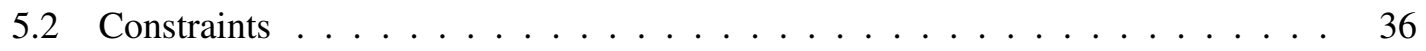

5.3 Optimization Results . . . . . . . . . . . . . . . . . . . . . 38

VI. BENCHTOP PROTOTYPE . . . . . . . . . . . . . . . . . . . . . . . . 40

6.1 Prototype Design . . . . . . . . . . . . . . . . . . . . . . 40

6.1 .1 Prototype Clutches . . . . . . . . . . . . . . . . . 40

6.1 .2 Prototype Sizing . . . . . . . . . . . . . . . . . . . 42

6.2 Experimental Evaluation . . . . . . . . . . . . . . . . . 43

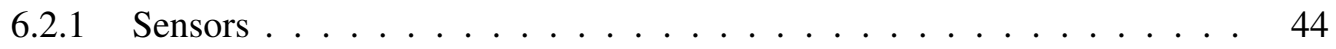

6.2 .2 Test Plan . . . . . . . . . . . . . . . . . 45

6.2 .3 Prototype Observations . . . . . . . . . . . . 46

VII. CONCLUSION AND FUTURE WORK . . . . . . . . . . . . . . . . . . . . 47

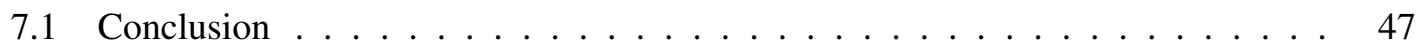

7.1 .1 Concept Design . . . . . . . . . . . . . . . . 47

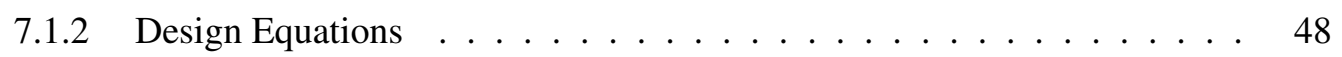

7.1 .3 Optimization . . . . . . . . . . . . . . . . . 49

7.1 .4 Prototype and Testing . . . . . . . . . . . . . . 50

7.2 Future Work . . . . . . . . . . . . . . . . . 50

7.2 .1 EPA Simulation . . . . . . . . . . . . . . 50

7.2.2 Increase Fidelity of the Optimization . . . . . . . . . . . . . 51

7.2 .3 Prototype Automation . . . . . . . . . . . . . . . 52

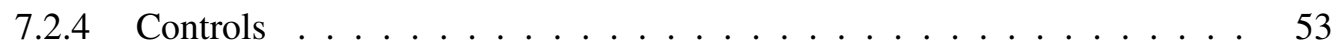

7.2 .5 Clutch Slip . . . . . . . . . . . . . . . 54

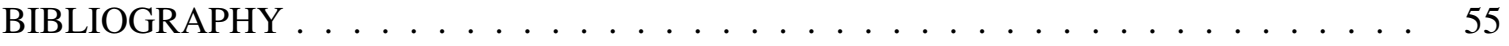




\section{LIST OF FIGURES}

1.1 Kinetic energy for a vehicle during a city simulation showing the kinetic energy lost

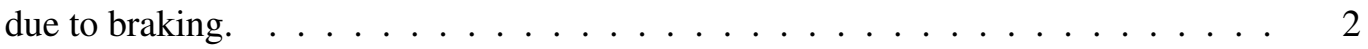

1.2 Regenerative braking concept from Volvo utilizing a flywheel to store the regener-

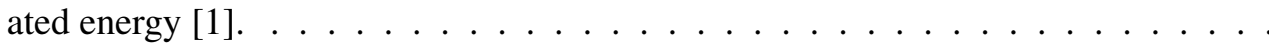

1.3 Regenerative braking concept for refuse trucks developed by Eaton utilizing pressurized fluids to store the regenerated energy [2]. . . . . . . . . . . . . 4

2.1 A concept sketch of the RBLA device showing each major component. . . . . . . . 8

2.2 Possible failsafe concept implemented to protect the RBLA if the pawl fails to disengage when the clutch engages. . . . . . . . . . . . . . 11

3.1 Free body diagram of the vehicle being propelled by the RBLA. . . . . . . . . . 17

3.2 Comparison between drag of different types of vehicles over a range of speeds, which the designed RBLA for a sedan can be seen by the red diamond. . . . . . . . 23

4.1 RBLA Simulated model created to validate the mathematical model. . . . . . . . 25

4.2 Simulation results of the RBLA from Launch Assist beginning at rest with a fully

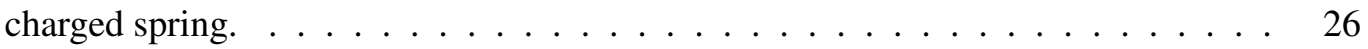

4.3 The EPA City Cycle velocity profile simulating urban driving. . . . . . . . . .

5.1 Spring deflection over the course of the EPA City Cycle. . . . . . . . . . 38

5.2 Spring deflection during a two minute portion of the EPA Cycle. . . . . . . . 39

6.1 A rendered section view of the prototype main shaft showing the floating shaft and all other components. . . . . . . . . . . . . . . . . . . . 
6.2 Rendered image of the completed benchtop prototype. . . . . . . . . . . . . 44

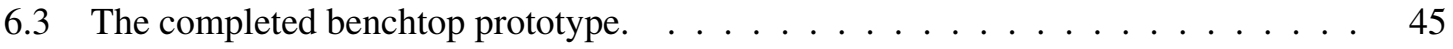

7.1 Specific Fuel Consumption at various engine speeds and energy outputs [3] . . . . 51 


\section{LIST OF TABLES}

2.1 RBLA modes of operation $\ldots \ldots \ldots \ldots \ldots \ldots$

4.1 Launch Assist Simulation Configurations _ . . . . . . . . . . . . . . . . 27

4.2 Launch Assist Simulation Results _ . . . . . . . . . . . . . . . . . . 28

5.1 Optimization parameters $\ldots \ldots \ldots \ldots \ldots \ldots \ldots \ldots$ 


\section{CHAPTER I}

\section{INTRODUCTION}

\subsection{Regenerative Braking}

With increasing fuel prices and an emphasis on sustainability, automotive manufacturers have placed substantial effort on making their vehicles more fuel efficient [4]. The rise of hybrid and electric vehicles are a result of the efforts to improve fuel efficiency [5]. However, hybrid and electric vehicles make up only $3 \%$ of the market [6]. The vast majority of vehicles on the road are still conventional vehicles with only an internal combustion (IC) engine. Using similar technology which the hybrid and electric vehicles implement, conventional automobiles may be able to increase efficiency with regenerative braking.

Currently, when a conventional vehicle slows down the brakes are applied and the kinetic energy is wasted. Regenerative braking is the harnessing of kinetic energy lost due to braking [7]. An example of the wasted energy is shown in Fig. 1.1, which the red line represents the kinetic energy dissipated to slow down the vehicle and wasted during a simulated urban driving course.

When regenerative braking is used in a closed system, the stored energy is used to later power the system. This concept has been used on vehicles dating back to an electric car in 1906 [8]. Over the years, various methods for both harnessing and storing the energy have been used, including chemical, electrical, and mechanical methods. 


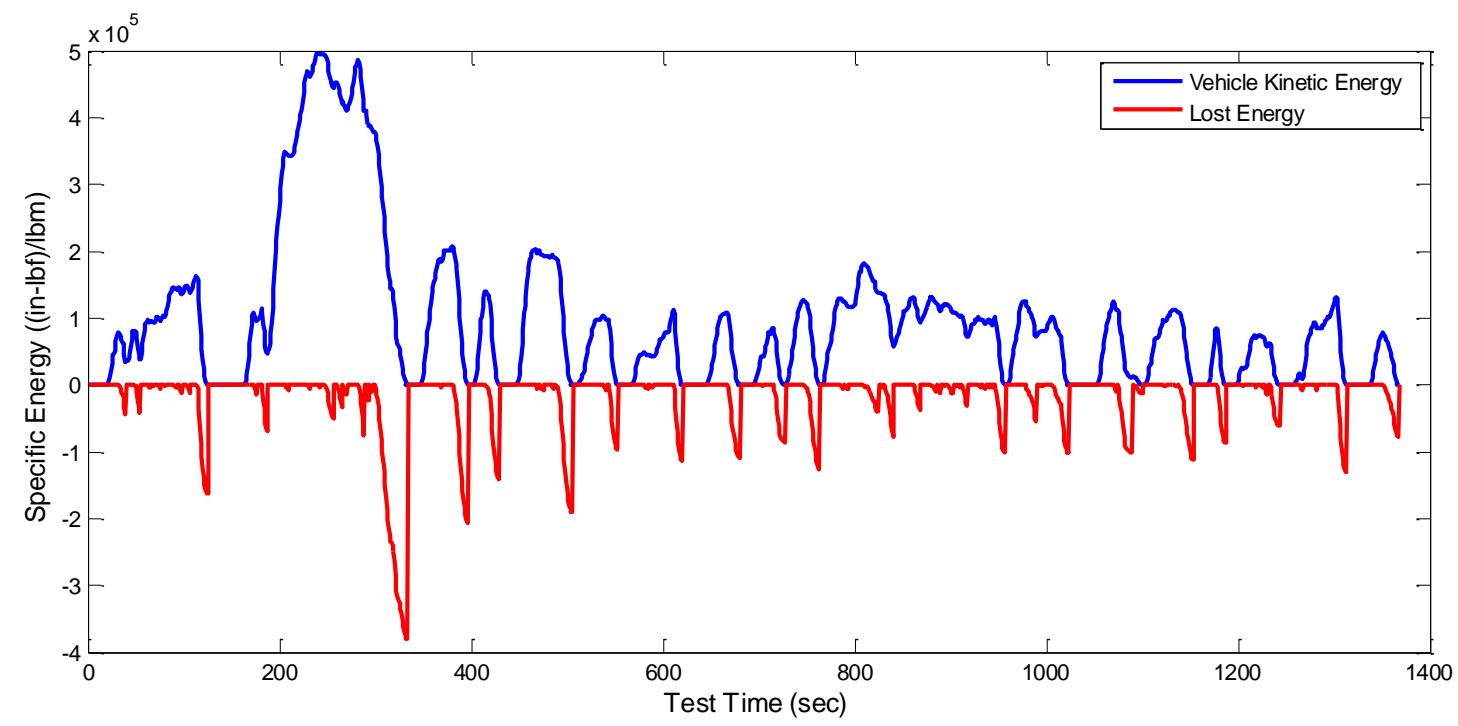

Figure 1.1: Kinetic energy for a vehicle during a city simulation showing the kinetic energy lost due to braking.

Regenerative braking is used in various fields; it has become widely known from current hybrid electric vehicles. Hybrids use a regenerative braking system that employs its electric motors to convert the kinetic energy of the vehicle into electricity when the car is braking. This energy is then stored in the batteries and used to subsequently propel the vehicle [9]. The number of energy transformations reduce the potential efficiency of the system. However, mechanical versions of regenerative braking have been used to assist IC engines and can improve their performance.

Mechanical versions of regenerative braking do not suffer from energy-mode conversion losses. Mechanical storage, such as Formula One Racing's KERS (kinetic energy recovery system) is regenerative braking that utilizes a flywheel. This high speed sport utilizes regenerative braking while approaching corners, storing the energy in an approximately 10 inch $(25 \mathrm{~cm}), 11$ pound $(5 \mathrm{~kg})$ flywheel with speeds up to $65,000 \mathrm{rpm}[10]$. When the race car accelerates, the energy from the 


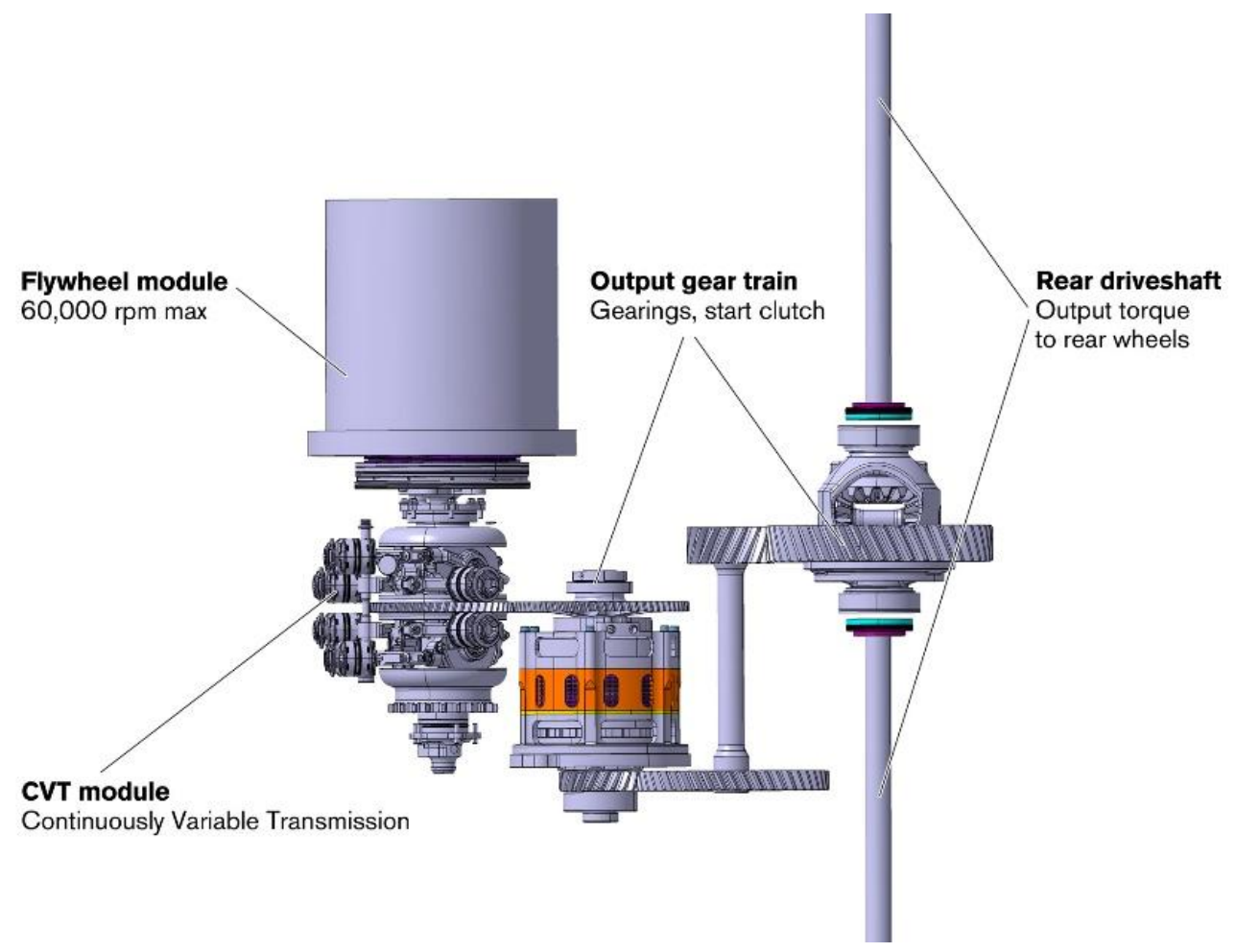

Figure 1.2: Regenerative braking concept from Volvo utilizing a flywheel to store the regenerated energy [1].

flywheel is released to provide large accelerations. This system is ideal in racing due to the need for high decelerations and accelerations. Yet, this system is not ideal for the average automobile user. A scaled down version has been developed by Volvo, named the KERS S60, implements a $6 \mathrm{lb}$ flywheel. The entire system weighs $130 \mathrm{lb}$ and is approximately the size of a three cylinder engine [1]. The KERS S60 is projected to increase efficiency by up to $25 \%$; installed values are not yet available. Long-term energy storage is not efficient using flywheels. KERS S60 loses the majority of its energy after 30 minutes without use [1]. Additionally, both KERS systems use a complex and costly continuously variable transmission (CVT) [11]. 
The Eaton Corporation developed a fluid pressurization regenerative braking system for refuse trucks and buses, the Hydraulic Launch Assist (HLA) [2]. During braking, this system utilizes a pump/motor to convert the kinetic energy by pressurizing hydraulic fluid. This pressurized fluid then compresses Nitrogen gas in a high pressure storage container. To use the stored energy, a valve releases the high pressure gas to the fluid in controlled portions to drive the pump/motor as a motor which creates torque propelling the vehicle. The HLA converts approximately $70 \%$ of the kinetic energy from its regenerative braking, which can improve the performance of refuse trucks from 15$30 \%$ depending on the cycle. The HLA works well for refuse trucks for two main reasons: the first is the frequent stops only a few yards apart, the second is refuse trucks weigh 64,000 pounds $(29,000$ $\mathrm{kg}$ ) on average [12]. The HLA weighs 1250 pounds $(550 \mathrm{~kg})$, which is nearly half the weight of a Honda Civic [13], yet only $2 \%$ of the refuse truck. Thus, it does not affect the mpg as greatly. This device would be difficult to scale down for consumer vehicles while maintaining efficiency.

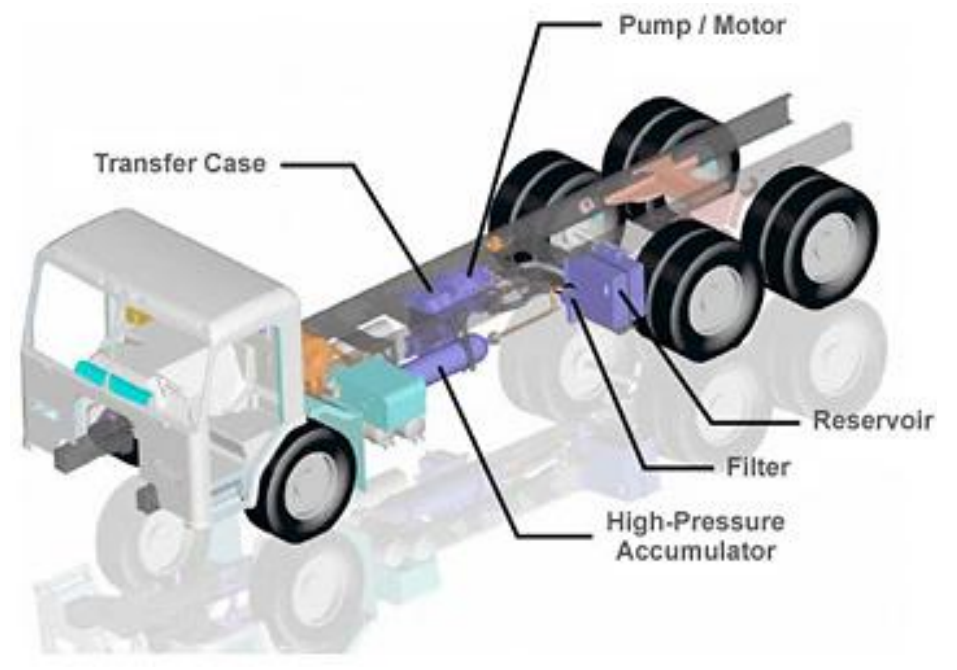

Figure 1.3: Regenerative braking concept for refuse trucks developed by Eaton utilizing pressurized fluids to store the regenerated energy [2]. 
Alternatively, Mazda has introduced the i-ELOOP which is a electric regenerative braking system for conventional vehicles. This system does not use the electricity to propel the vehicle, it uses the regenerated electricity to power the accessories such as climate control and the radio [14]. The majority of the savings come from the integration of the stop-start system. The engine will turn off while the vehicle is not in motion then the capacitor that stores the regenerated energy is used to start the vehicle. This system has the greatest effect on a vehicle when frequently coming to complete stops or during heavy use of the electronics. The i-ELOOP is advertised to increase the fuel economy by as much as $10 \%$, but installed values are not yet available.

\subsection{Spring Based Regenerative Braking and Launch Assist System}

This thesis project explores the potential for a spring based regenerative braking and launch assist system (RBLA) to allow conventional consumer vehicles the ability of regenerative braking, an idea patented by Lyle Hoppie over 30 years ago $[15,16,17]$. Strain energy, or springs, are one of the most basic forms of energy storage. At approximately $0.3 \mathrm{~kJ} / \mathrm{kg}$ [18], the specific energy density of a steel spring is much less than $100 \mathrm{~kJ} / \mathrm{kg}$ of car batteries [19] and is not commonly considered as a viable option for wide-spread, high energy storage. However, the spring is an environmentally friendly alternative to batteries while being reliable and durable. Additionally, springs have the ability to quickly expel energy, unlike batteries.

This thesis project follows the development of the RBLA. For the RBLA to have the greatest impact on the fuel efficiency a vehicle, the design is optimized. First, the device and its effect on the vehicle was broken down by the physics of defining the system. Then a mathematical model of the RBLA and vehicle was created and validated by dynamic simulations. This mathematical model was used to simulate the RBLA installed on a vehicle throughout a cycle simulating urban driving. The amount of energy the RBLA was able to regenerate and subsequently propel the vehicle is 
calculated to find its effect on the fuel efficiency. The mathematical model simulated over a urban driving cycle was then used within an optimization which sized each component to create an optimal design. Finally, a prototype of the RBLA was tested for its functionality.

\subsection{Overview}

The remainder of the thesis is organized as follows. Chapter 2 describes the RBLA concept. Chapter 3 develops the mathematical model of the RBLA and design equations. Chapter 4 presents a dynamic simulation preformed to confirm the design equations. An optimization to determine ideal design values is presented in Chapter 5. A benchtop prototype to prove the concept is described in Chapter 6. The conclusion and future work is presented in Chapter 7. 


\section{CHAPTER II}

\section{THE REGENERATIVE BRAKING AND LAUNCH ASSIST DEVICE}

\subsection{Description of Concept}

A concept for a spring based regenerative braking and launch assist system (RBLA) is proposed in this thesis project. The system is decomposed to the necessary requirements, determining the initial concept. From the concept, each component was selected to fulfill the necessary requirements. Finally, the specific type of each component was then chosen.

\subsubsection{Concept Requirements}

A spring based mechanical regenerative braking and launch assist system must be able to use the spring to slow the vehicle while storing energy (RB mode) as well as accelerate the vehicle while releasing energy from the spring (LA mode). This concept was designed to be placed on the non-drive axle of the vehicle (the rear axle for front-wheel drive vehicles). Attaching to the nondrive axle will limit the controls to interface with the drive-train. Additionally, the non-drive axle is typically large enough to handle the loads produced from the RBLA.

The axle only rotates in one direction while the vehicle is in forward motion, thus the design must be able to allow for this single direction of motion during both the regeneration mode as well as the launch assist mode. In most strain devices, the deformation and relaxation cycle involves a 
reversal in direction. The RBLA mechanism is intended to function only when the vehicle is moving forward, thus it must account for the reversal of the storage element.

The regenerative braking and launch assist modes should only be active while the car is accelerating or decelerating, when the vehicle is at a constant speed the device should be inactive. Ideally, the device should produce minimal effects on to the vehicle while not in use. Thus this device must engage and disengage from the axle.

\subsubsection{Concept Design}

There are four major components to the RBLA as shown in the sketch of the concept in Fig. 2.1.

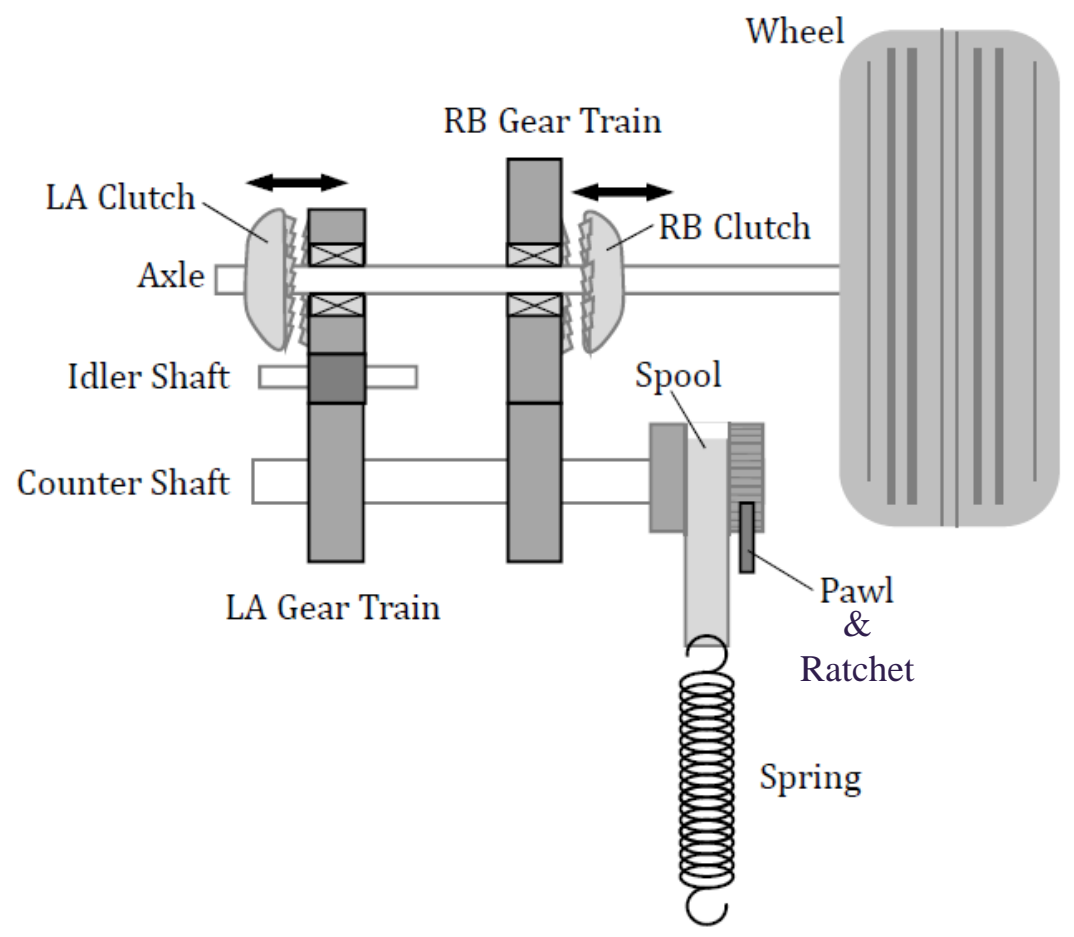

Figure 2.1: A concept sketch of the RBLA device showing each major component. 
I The spring is attached to a counter shaft that parallels the vehicle's non-drive axle. A variety of types of strain-based storage devices can be implemented in this design. Torsional springs can attach directly to the countershaft. Linear springs can attach to a strap that winds onto a spool mounted onto the countershaft, as seen in Fig. 2.1.

II Two gear trains transmit the spring torque to/from the axle. The gears mounted to the axle contain bearings which are pressed into their bores permitting independent rotation of the gears and axle. Each gear train is used independently, depending if the device is in RB or LA mode. One gear train contains an idler to account for the change in direction of the transmitted torque. Alternatively, a belt or chain can be used to achieve the necessary motion.

III Two clutches are used to connect the gears mounted on the axle and the axle itself. One side of each clutch is rigidly fixed onto the axle and the other side of each clutch is rigidly attached to the corresponding gear. Only one clutch is engaged at a time, depending on the RB or LA mode. Engaging the RB clutch allows the transmission of torque from the axle to the countershaft, slowing the vehicle. Engaging the LA clutch allows the transmission of torque from the countershaft to the axle, accelerating the vehicle. The clutches must be sized to quickly bring the RBLA and axle to the same speed with minimal slippage.

IV A pawl and ratchet are used on the countershaft for idle mode. This will prevent any movement of the spring when both clutches are disengaged.

\subsubsection{Concept Modes}

Three modes are used in the RBLA mechanism: storage or regenerative braking (RB), discharge or launch assist (LA), and idle. As the RBLA is in storage mode, the spring deforms as it stores energy. The spring returns to its original shape as the RBLA discharges and energy releases during 
the LA mode. The idle mode retains any charge in the spring and makes the RBLA inactive allowing the vehicle to function as normal. The configurations for the major components during each operational mode is given in Table 2.1 .

Table 2.1: RBLA modes of operation

\begin{tabular}{|l||c|c|c|}
\hline & Idle & Storage (RB) & Discharge (LA) \\
\hline \hline Pawl & Engaged & Overridden & Disengaged \\
\hline RB Clutch & Disengaged & Engaged & Disengaged \\
\hline LA Clutch & Disengaged & Disengaged & Engaged \\
\hline Spring & Static & Storing & Discharging \\
\hline
\end{tabular}

When the RBLA is idle, the pawl is engaged and the spring does not discharge until the pawl is released, retaining energy, if any. Both clutches are disengaged and, since the gears are floating on the axle, the RBLA is not in motion when the device is idle. The performance of the vehicle is minimally effected while the RBLA is idle. The drag from two bearings and the spinning of the small clutch discs can be considered negligible.

During the storage mode the RB clutch is engaged rotating the countershaft in the direction that overruns the pawl while the spring stores energy. The RBLA regenerates energy until either the spring reaches full capacity or the vehicle deceleration is no longer desired. Regenerative braking is activated when the brake pedal is applied and the spring is not fully charged. This mode may be used simultaneously with conventional friction brakes if a higher rate of deceleration is desired.

While discharging, the pawl is released and the LA clutch is engaged simultaneously. The spring discharges, which propels the vehicle forward until the spring discharges all energy or the vehicle 
acceleration is no longer desired. Launch assist is activated when the gas pedal is depressed. This mode may be used simultaneously with the engine when higher accelerations are required.

Some spring energy will be lost if the pawl is released before the clutch is engaged. This is the stage in which the spring has the greatest amount of energy, thus it will quickly loose energy until the clutch is fully engaged. If the clutch engages before the pawl is released the clutch will be forced to slip or the pawl failsafe will activate. This failsafe is designed to release the pawl when a force higher than the maximum spring force is applied, a result of the clutch engaging too early. A possible failsafe may mount the pawl to a friction surface which slips when the rated force is surpasses, then returns with the use of a failsafe spring as seen in Fig. 2.2.

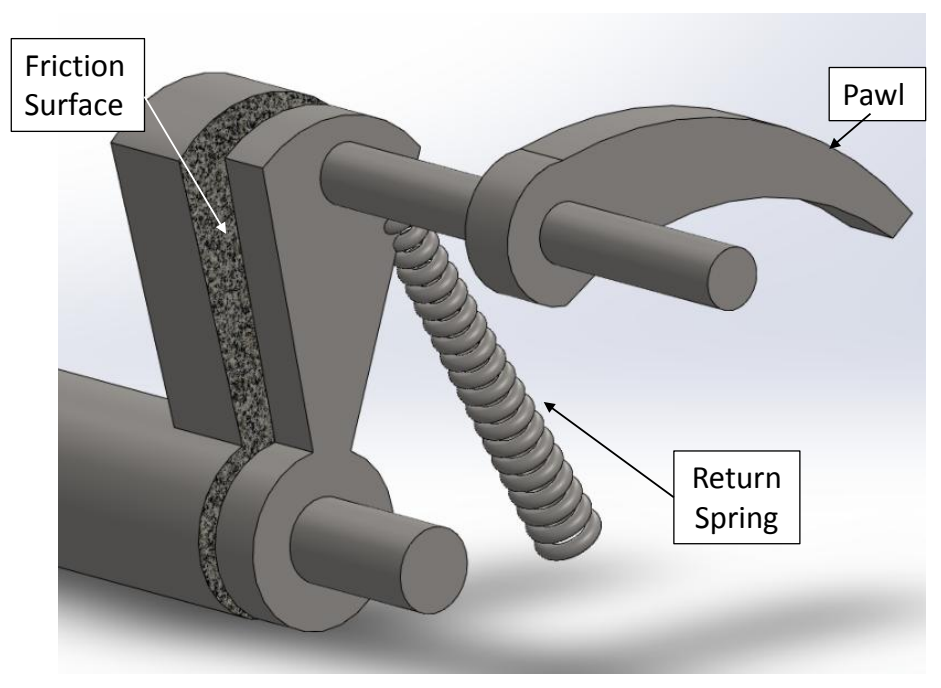

Figure 2.2: Possible failsafe concept implemented to protect the RBLA if the pawl fails to disengage when the clutch engages. 


\subsubsection{Concept Controls}

The initial RBLA concept is designed to be installed onto the non-drive shaft of a two-wheel drive vehicle. This lessens the necessary controls of the system. The RBLA requires two criteria for activation for each mode. First, if the vehicle gas pedal is depressed while the spring is deformed, the launch assist mode is activated. This mode remains active until the spring is no longer deformed or the gas pedal is released. Second, if the brake pedal is depressed while the spring is not fully deformed, the regenerative braking mode is activated until the spring is fully deformed or the brake pedal is released. Proximity sensors or limit switches could monitor when the spring is fully charged or fully discharged. An integrated circuit can monitor the logic cues which activate and deactivate the RBLA.

While charging or discharging, the spring is constantly changing the level of deformation, thus the torque affecting the vehicle acceleration also changes. Hence, the RBLA is not designed to be the sole means to propel or stop the vehicle. The RBLA is activated at the initial press of either the brake pedal or accelerator. If either pedal is depressed further the engine or brakes will activate simultaneously with the RBLA, respectively. For example during launch assist, the spring applies torque to the wheels. As soon as the accelerator is depressed the spring will be released, as long as there is energy in the spring. For a higher acceleration, the accelerator is depressed further and the front wheels have an additional torque applied from the engine. Since there will be two sources of torque, the drive wheels will dictate the speed the car moves, while the RBLA will lessen the torque required from the engine.

Regenerative braking is a similar scenario yet the engine is replaced by brakes, which mirrors the hybrid-electric vehicle controls [20]. When the brake pedal is depressed, the RB engages and stores energy in the spring, as long as the spring is not at its maximum. For a larger deceleration, 
the brake pedal is depressed further and the brakes engage. Both the RBLA and brakes will provide torque on the wheels to slow the vehicle.

The peak acceleration of the RB and LA cycles are limited to comfortable rates, as defined by Gebhard [21]. Thus, the RBLA will aid accelerations, not define them. Each mode will have the least effect on vehicle speed when the spring is closest to fully discharged, and the greatest effect (greatest accelerations) when the spring is closest to fully charged. Further work will study the relationship between RBLA energy level and location of pedal activation.

\subsection{Springs}

Springs are elastic members that deform to store energy. Springs have been used as a source of energy storage in clocks, bows, and animal traps for centuries. One of the most common springs are coil extension springs, however there are many types of springs.

Springs can be defined by how the loads are applied, their shape, or movement. Many springs are metal and coiled, such as extension, compression, and torsional springs [22]. Extension and compression springs have load applied inline with the main axis and change length under loading. Torsion springs have the load applied as a moment about the main axis. These springs have small changes in diameter from fully charged to fully discharged. Flat springs are often made of of flat or conical piece of metal, such as tweezers, the diaphragm in a car clutch, or leaf springs in a vehicle suspension. These springs often have smaller travel and a higher stiffness [23].

The most common material used in springs is steel which has a specific energy density of 0.3 $\mathrm{kJ} / \mathrm{kg}$ [18]. Hyperelastic springs, such as rubber, have much a larger energy density of $12 \mathrm{~kJ} / \mathrm{kg}$ [18], but further research studies must be completed to find the fatigue life of these materials at high strain. Ongoing research by Hill et al. involves constructing springs from carbon nano-tubes, having an energy density of $800 \mathrm{~kJ} / \mathrm{kg}$, greatly exceeding the capacity of batteries [24]. Since this 
is ongoing research, the manufacturability and market availability of carbon nano-tube springs are open questions.

The simplicity, low cost, and minimal environmental effects of springs make them an ideal candidate for energy storage. At approximately $0.3 \mathrm{~kJ} / \mathrm{kg}$ [18], the specific energy density of a steel spring is much less than $100 \mathrm{~kJ} / \mathrm{kg}$ of car batteries [19] and not commonly considered as a viable option for wide-spread, high energy storage. However, the spring is an environmentally friendly alternative to batteries while being reliable and durable.

Current research is being conducted by the DIMLab at the University of Dayton to find the best spring for this application [25]. The relationships between size, weight, energy, and fatigue life are all being compared to find the optimal spring. Since this is ongoing research, the RBLA is designed to be used with various types of springs (i.e. extension, torsion, leaf, etc.). Steel extension springs have been selected as the initial spring type.

\subsection{Clutches}

Clutches are often implemented to bring two spinning masses to the same speed [23]. Clutches are used to both limit torque, such as power drills, or transfer torque, such as the transmission of an automobile. Slippage, the period the two surfaces are in contact but not at the same speed, occurs in the fractions of a second following a clutch actuation. This can be advantageous, as the case of car brakes, the rotating axle is slowed by the stationary brakes. A clutch may be designed for high slippage, such as brakes, or low slippage, as desired for the RBLA, which will reduce the overall energy losses.

Clutches are categorized by the direction of the actuation force:

Centrifugal clutches are often used as automatic clutches but can be actuated electrically, hydraulically, or pneumatically [23]. These clutches are also called expanding ring clutches since the 
clutch pads are internal to a cylinder and expand to make contact with the outer cylinder. These benefit from the centrifugal force aiding the actuation force.

Axial clutches are actuated in the direction of the shaft axis. A disc clutch is the most common form. These clutches have the frictional surfaces on the face of the disc that interact with a flat surface, typically steel [26]. The popularity of these clutches is due to the compact packaging abilities as well as the large frictional areas. Multiple discs may be used, such as clutch baskets in motorcycles, or one large disc may be implemented, as in automobiles. Additionally, these clutches can be both wet (lubricated) or dry (not lubricated). The actuation force is often implemented by a spring and a release force, or throwout force, is applied to disengage the clutch. This allows for consistent torques and wear patterns.

Clutches are designed for friction, thus they must have high resistance to wear. Materials are selected for their high and reproducible coefficient of friction, resistance to wear, and ability to withstand high temperatures [23]. Common materials for clutches include asbestos, ceramic, carbon graphite, and other composites.

Clutches are selected to efficiently account for the large difference in speeds between the axle and the RBLA upon activation. Clutches are commonly used and are reliable automotive components with well known performance characteristics. The clutches selected for the RBLA are made with similar material as the existing vehicle transmission clutch and will have a similar maintenance schedule. 


\section{CHAPTER III}

\section{DESIGN EQUATIONS}

\subsection{RBLA Mathematical Model}

The following section provides the development of the mathematical model of the RBLA and its effect on a vehicle. This model accounts for the effect of the spring on the movement of the vehicle as well as the vehicle's effect on the RBLA. Additionally, the model formed is used to define the design space for the RBLA and size each component.

\subsubsection{Equations of Motion Method}

A free body diagram of an automobile of mass $m_{c}$ being propelled by the RBLA is shown in Fig. 3.1. The principle vehicle forces include the aerodynamic drag $F_{D}$, the weight $W=m_{c} g$, the normal forces on the tires $N_{1}$ and $N_{2}$, and the thrust $F_{T}$ from the launch assist. The vehicle motion coordinate $x_{c}$ is also defined in Fig. 3.1 with velocity $\dot{x}_{c}$ and acceleration $\ddot{x}_{c}$. Note that $F_{T}$ can be either in the direction of motion $\dot{x}_{c}$, or against $\dot{x}_{c}$, depending on the mechanism mode, RB or LA.

Summing the forces in the direction of motion,

$$
F_{T}-F_{D}-W \sin \psi=m_{c} \ddot{x}_{c}
$$

The drag force of the vehicle is dependent on the reference frontal area $S$, the coefficient of drag $C_{D}$, the air density $\rho_{a}$, and the speed of the air with respect to the vehicle (assumed to be the speed 


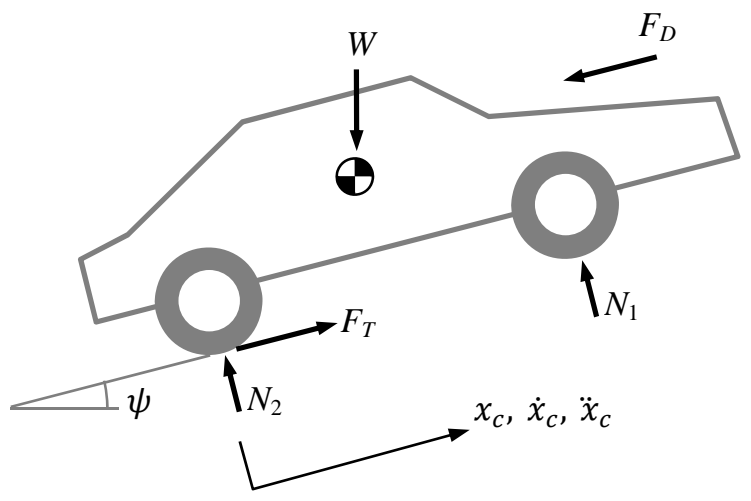

Figure 3.1: Free body diagram of the vehicle being propelled by the RBLA.

of the vehicle $\dot{x_{c}}$ ).

$$
F_{D}=\frac{1}{2} C_{D} S \rho_{a}{\dot{x_{c}}}^{2}
$$

The RBLA has a velocity ratio $R_{v}$ between the rotation angle of the counter shaft carrying the spring spool $\theta_{s}$ and rotation angle of the axle $\theta_{w}$,

$$
\theta_{s}=R_{v} \theta_{w}
$$

The spring spool and tire have a radii $r_{d}$ and $r_{w}$, respectively. The energy storage spring has a stiffness of $k$ and is deflected an amount $x_{s}$. Using the relation $\theta_{s}=x_{s} / r_{d}$ and $\theta_{w}=x_{c} / r_{w}$, with an initial deflection of $x_{s_{0}}$, the relationship between the displacement of the car and the spring deflection is

$$
x_{c}=\left(\frac{r_{w}}{R_{v} r_{d}}\right)\left(x_{s_{0}}-x_{s}\right) .
$$

A spring force of $F_{s}=k x_{s}$ produces a torque on the countershaft of

$$
T_{s}=r_{d} k x_{s}
$$

and transferring that torque to the wheel axle using Eq. (3.3) produces

$$
T_{w}=R_{v} r_{d} k x_{s}
$$


Summing torques on the axle,

$$
R_{v} r_{d} k x_{s}-F_{T} r_{w}=J \ddot{\theta}_{w}
$$

where $\ddot{\theta}_{w}$ is the rotational acceleration of the axle and $J$ is the effective rotational inertia of the RBLA system and the vehicle wheels. Note that $\ddot{\theta}_{w}=\ddot{x}_{c} / r_{w}$. Thus, the thrust force produced by the spring is

$$
F_{T}=\frac{R_{v} r_{d} k x_{s}}{r_{w}}-\frac{J}{r_{w}^{2}} \ddot{x}_{c}
$$

Substituting Eqs. (3.8) and (3.2) into Eq. (3.1),

$$
\frac{R_{v} r_{d}}{r_{w}} k x_{s}-\frac{J}{r_{w}^{2}} \ddot{x}_{c}-\frac{C_{D} S \rho_{a}}{2} \dot{x}_{c}^{2}-W \sin \psi=m_{c} \ddot{x}_{c}
$$

Substituting Eq. (3.4) into Eq. (3.9), produces the equation of motion for a vehicle including a spring with the initial deflection $x_{s_{0}}$

$$
\left(m_{c}+\frac{J}{r_{w}^{2}}\right) \ddot{x}_{c}+\frac{C_{D} S \rho_{a}}{2} \dot{x}_{c}^{2}+\frac{R_{v}^{2} r_{d}^{2}}{r_{w}^{2}} k x_{c}=\frac{R_{v} r_{d}}{r_{w}} k x_{s_{0}}-W \sin \psi
$$

Equation (3.10) is a classic single degree-of-freedom dynamic system. It models both the regenerative mode as well as the launch assist mode, in which $R_{v}$ will be negative for the RB mode. Focusing on a launch, the relatively low speed will allow $F_{D}$ to be negated. The vehicle response solution to the classic spring mass system of Eq. (3.10), when releasing the spring with initial deflection $x_{s_{0}}$ is

$$
x_{c}=A \cos (\omega t+\phi)-\frac{r_{w} x_{s_{0}}}{R_{v} r_{d}}+\frac{r_{w}^{2} W \sin \psi}{R_{v}^{2} r_{d}^{2}},
$$

where the system natural frequency is

$$
\omega=\sqrt{\frac{\text { Stiffness }}{\text { Inertia }}}=\sqrt{\frac{R_{v}^{2} r_{d}^{2} k}{r_{w}^{2} m_{c}+J}} .
$$

If the vehicle is propelled from rest, $\phi=\pi$. Control of the clutches will prohibit the vehicle response beyond the time where the spring reaches its maximum deflection, $x_{s_{\max }}$, which also 
limits $\dot{x}_{c} \leq \dot{x}_{c_{\max }}$. Substituting $x_{c}=0$ at $\omega t=0$ into Eq. (3.11),

$$
A=\frac{r_{w} x_{s_{0}}}{R_{v} r_{d}}-\frac{r_{w}^{2} W \sin \psi}{R_{v}^{2} r_{d}^{2}}
$$

Taking the time derivative of Eq. (3.11),

$$
\begin{gathered}
\dot{x}_{c}=A \omega \sin (\omega t-\pi), \\
\ddot{x}_{c}=A \omega^{2} \cos (\omega t-\pi) .
\end{gathered}
$$

The vehicle will reach its top speed $\dot{x}_{c_{\max }}$ at a time $t_{s}$. It is observed from Eq. (3.14) that $\dot{x}_{c}$ is maximum when $\omega t_{s}=\pi / 2$. Thus,

$$
t_{s}=\frac{\pi}{2} \sqrt{\frac{r_{w}^{2} m_{c}+J}{R_{v}^{2} r_{d}^{2} k}}
$$

Also from Eq. (3.14), the maximum vehicle speed obtained by the spring stretch of $x_{s_{0}}$ is

$$
\dot{x}_{c_{\max }}=A \omega .
$$

Likewise, the maximum vehicle acceleration is

$$
\ddot{x}_{c_{\max }}=A \omega^{2} .
$$

Substituting Eq. (3.12) into Eq. (3.17),

$$
\dot{x}_{c_{\max }}=\left(r_{w} x_{s_{0}}-\frac{r_{w}^{2} W \sin \psi}{R_{v} r_{d}}\right) \sqrt{\frac{k}{r_{w}^{2} m_{c}+J}},
$$

and substituting Eq. (3.12) into Eq. (3.18),

$$
\ddot{x}_{c_{\max }}=\left(R_{v} r_{d} r_{w} x_{s_{0}}-r_{w}^{2} W \sin \psi\right) \frac{k}{r_{w}^{2} m_{c}+J} .
$$

Equations (3.11), (3.19), and (3.20) will be used to determine the effect of the RBLA on the vehicle performance. Both the regenerative mode as well as the launch assist mode are modeled with the mathematical model by using the appropriate value for the gear ratio. 


\subsubsection{Energy Method}

The system was additionally modeled on level terrain using Conservation of Energy between three forms. Kinetic energy of the moving vehicle accounts for the vehicle weight and the RBLA weight as well as the acceleration of the vehicle. The kinetic energy is initially modeled as a vehicle starting from rest to the maximum launched velocity (equal to the maximum regenerated velocity). Rotational kinetic energy accounts for the moment of inertia of the RBLA and axle assembly of the vehicle about the axis of the axle. Spring energy is the final term, accounting for the spring stiffness and deflection. The spring deflects from its maximum deflection to the free length in this example.

$$
E_{c}=\frac{1}{2} m_{c} \dot{x}_{c}^{2}+\frac{1}{2} J \dot{\theta}_{w}^{2}-\frac{1}{2} k x_{s}^{2}
$$

Assuming a no slip condition between the wheel and the road, the angular velocity $\left(\dot{\theta}_{w}\right)$ is substituted for the velocity of the vehicle using the wheel size,

$$
\dot{\theta}_{w}=\frac{\dot{x}_{c}}{r_{w}}
$$

During launch, all spring energy is converted to kinetic energy,

$$
k x_{s}^{2}=m \dot{x}_{c}^{2}+J \dot{\theta}_{w}^{2}
$$

Substituting Eq. (3.22) into Eq. (3.23),

$$
\dot{x}_{c_{\max }}=r_{w} x_{s} \sqrt{\frac{k}{m_{c} r_{w}^{2}+J}} .
$$

Equation (3.24) provides a relation for maximum launched speeds which an RBLA can achieve independently. This equation, derived from the Conversation of Energy, matches the equation produces from the equation of motion method, Eq. (3.19).

The torque about the axle is analyzed to model the vehicle acceleration and account for the gear ratio. The torque to accelerate the mass of the vehicle creates a torque on the wheels. Drag and 
road slope are negated. Inertial torque accounts for the rotation of the axle assembly as well as the RBLA. The spring creates a torque from the spool through a gear ratio to the axle,

$$
T_{w}=r_{w} m_{c} \ddot{x}_{c}-J \ddot{\theta}_{w}+k x_{s} R_{V} r_{d}
$$

The rotational acceleration of the wheel can be substituted for the acceleration of the vehicle, assuming a no slip condition,

$$
\ddot{\theta}_{w}=\frac{\ddot{x}_{c}}{r_{w}}
$$

Solving for the acceleration of the vehicle,

$$
\ddot{x}_{c_{\max }}=\frac{R_{V} r_{w} r_{d} k x_{s}}{J+m_{c} r_{w}^{2}}
$$

Equations (3.24) and (3.27) are identical to Eqs. (3.19) and (3.20) validating the formulation.

The RBLA can now be designed as a direct relation to its effect on the vehicle. Of the ten variables in (3.11), (3.16), (3.19), and (3.20) three are motion terms $\left(x_{c}, \dot{x}_{c}, \ddot{x}_{c}\right)$, two are prescribed vehicle parameters $\left(m_{c}\right.$ and $\left.r_{w}\right)$, and the rest are design variables $\left(R_{v}, r_{d}, J, k, x_{s_{0}}\right)$. Note that $m_{c}$ and $J$ vary slightly with the selection of RBLA components. These design variables, with the addition of spring sizing variables, design the RBLA.

\subsubsection{Extension Spring Equations}

For the feasibility study, a steel helical extension spring was selected due to its widespread use for storing energy (specifically in garage doors). An extension spring stiffness is [23]

$$
k=\frac{d^{4} G}{64 D^{3} N_{a}}
$$

where $d$ is the spring wire diameter, $G$ is the shear modulus of elasticity of the spring material, $D$ is the mean coil diameter, and $N_{a}$ is the number of active coils. The maximum torsional stress in the 
spring wire is

$$
\tau_{\max }=\frac{K_{i} G d x_{s_{\max }}}{8 \pi D^{2} N_{a}}
$$

where $x_{s_{\max }}$ is the maximum allowable spring extension, $K_{i}$ is a stress concentration factor,

$$
K_{i}=\frac{4 C-1}{4 C-4}+\frac{0.615}{C},
$$

and $C=D / d$ is the spring index.

\subsection{Justification for Negating the Drag Force}

In the mathematical model aerodynamic drag was negated, Eq. (3.11), this claim is now investigated. Drag is dependent on two vehicle specific parameters, the coefficient of $\operatorname{drag} C_{D}$ and the frontal area $S$, Eq. (3.2). The coefficient of drag does not vary significantly between vehicles. The difference between a Corvette, an SUV, and a sedan is 10\% (.29-.32), with the SUV and Corvette having similar values. The major influence on drag for vehicles is the frontal area, which the SUV nearly doubles that of the sedan and Corvette $\left(6.3-11.6 \mathrm{ft}^{2}\right)$ [27].

It is assumed the energy to overcome drag will be produced by the engine while the engine is in use. The scenario to be tested is a pure launch assist situation: a fully charged spring, the vehicle starting at rest, and no aid from the engine. The proposed, optimized RBLA for a sedan has a maximum pure launch speed of $20.53 \mathrm{ft} / \mathrm{s}(14 \mathrm{mph})$. The drag on the vehicle is $3.2 \mathrm{lb}(1.5 \mathrm{~N})$, using Eq. (3.2), this is less than $0.04 \%$ of the maximum spring force. However, as seen in Fig. 3.2, the drag increases quadratically as the speed increases, thus negating drag is a safe assumption at low speeds. 


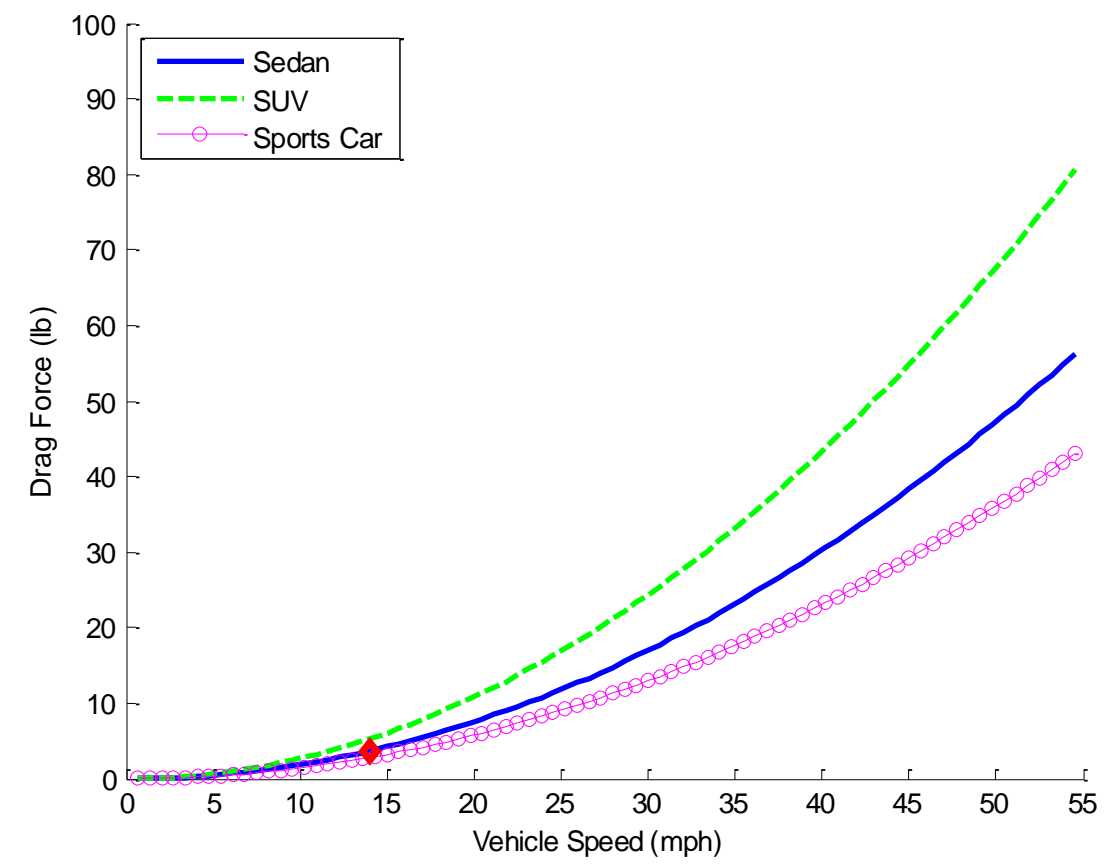

Figure 3.2: Comparison between drag of different types of vehicles over a range of speeds, which the designed RBLA for a sedan can be seen by the red diamond. 


\section{CHAPTER IV}

\section{SIMULATION}

\subsection{Simulation Assumptions}

A multibody dynamic motion simulation was performed using the Autodesk Inventor and Dassault System's Solidworks packages to validate the design equations. These software packages have the ability to simulate motions and interaction forces between components. The RBLA system that is simulated contained only the moving parts of the device concept (gears, spring, shafts, and spool) as seen in Fig. 4.1. The vehicle was modeled as a rigid mass. All non-moving aspects of the RBLA were assumed to move rigidly with the vehicle, thus simply modeled as a portion of the vehicle mass.

The values in the model are based on an average consumer sedan, using its wheel size (12 in./ $31 \mathrm{~cm}$ diameter) and vehicle mass $(2,000 \mathrm{lb} / 900 \mathrm{~kg})$. After modeling each component, the mass properties were specified to match the original motion equations, matching the mass assuming each component is a cylinder. Additionally, the moment of inertia values which were generated from the modeling package were also over-ridden to match the motion equation values for consistency between the simulation and motion models. The moment of inertia for the purely cylindrical components, such as the shafts and gears, are similar to the formulated cases when the material was applied in the software. However, the simulated wheel had to be specified to match an actual wheel's $J$ value [28]. Finally, the vehicle mass was applied to a simulated road. Since the simulation is 


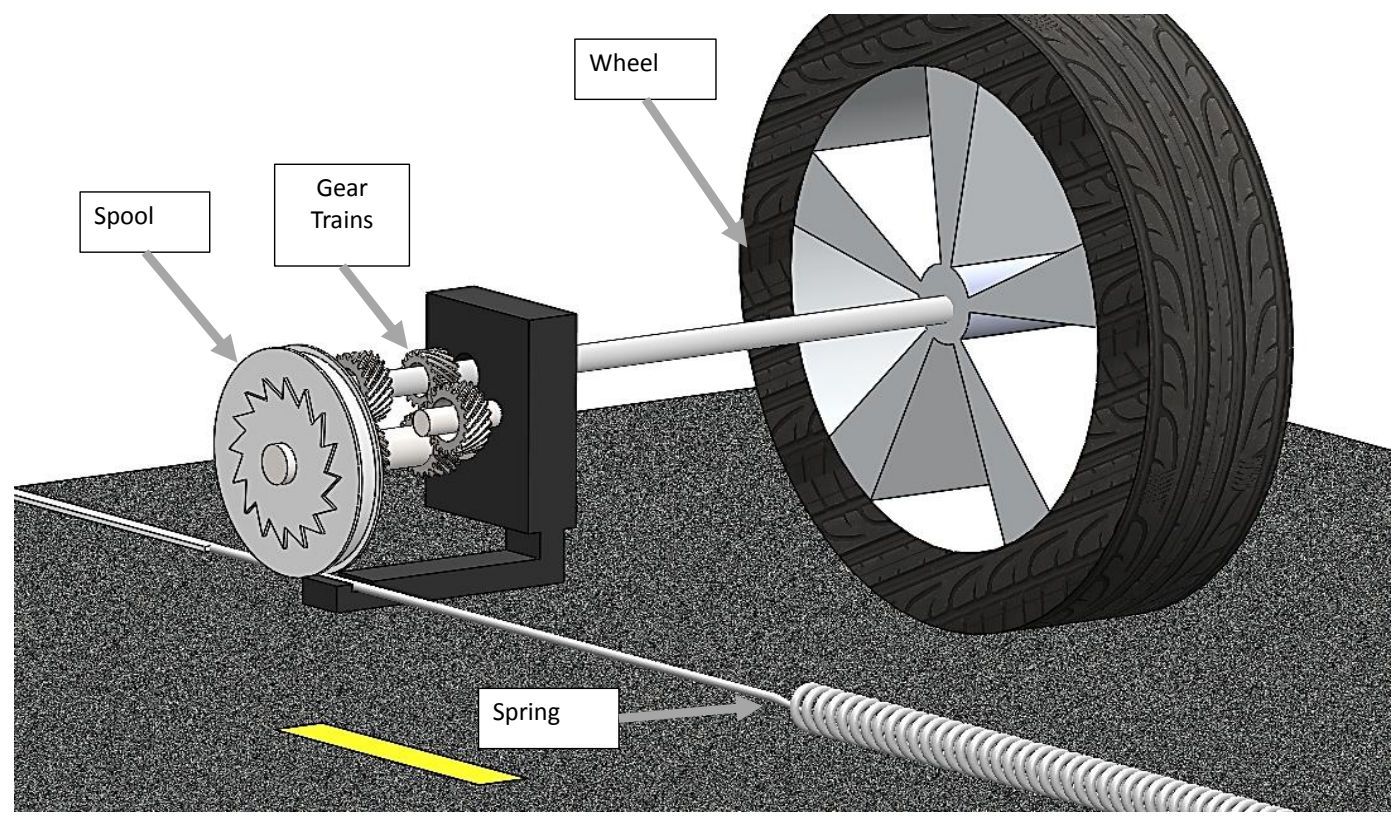

Figure 4.1: RBLA Simulated model created to validate the mathematical model.

constrained to purely in-plane translational motion, the location of the center of gravity of the vehicle did not need to be modeled. Additionally, the force exerted to move a vehicle with a given mass from a grounded object (the road) is equal to the force to move an object with the same mass with respect to a grounded vehicle. Thus, the road was over-ridden with the vehicle mass and the RBLA remained stationary. This assumption neglects any change in vehicle pitch during the acceleration of the RBLA, this is a valid assumption since the maximum acceleration that the RBLA propels the vehicle is set to a comfortable speed [21]. The spring constant and initial deformation were also specified within the simulation. This model allowed several simulations to be preformed.

\subsection{Pure Launch Assist}

The initial simulation tested was pure launch assist. This example simulates launch assist starting from rest $\left(\dot{x}_{c}=0\right)$, expelling the maximum energy the spring is able to retain, concluding when 
the spring returns to its undeformed length $\left(x_{s}=0\right)$. The simulation was conducted on flat pavement $(\psi=0)$ and did not include frictional losses between the RBLA components. Additionally, since the maximum launch speed is low, drag forces were neglected $\left(F_{D}=0\right)$. The simulation results of one case are shown in Fig. 4.2.

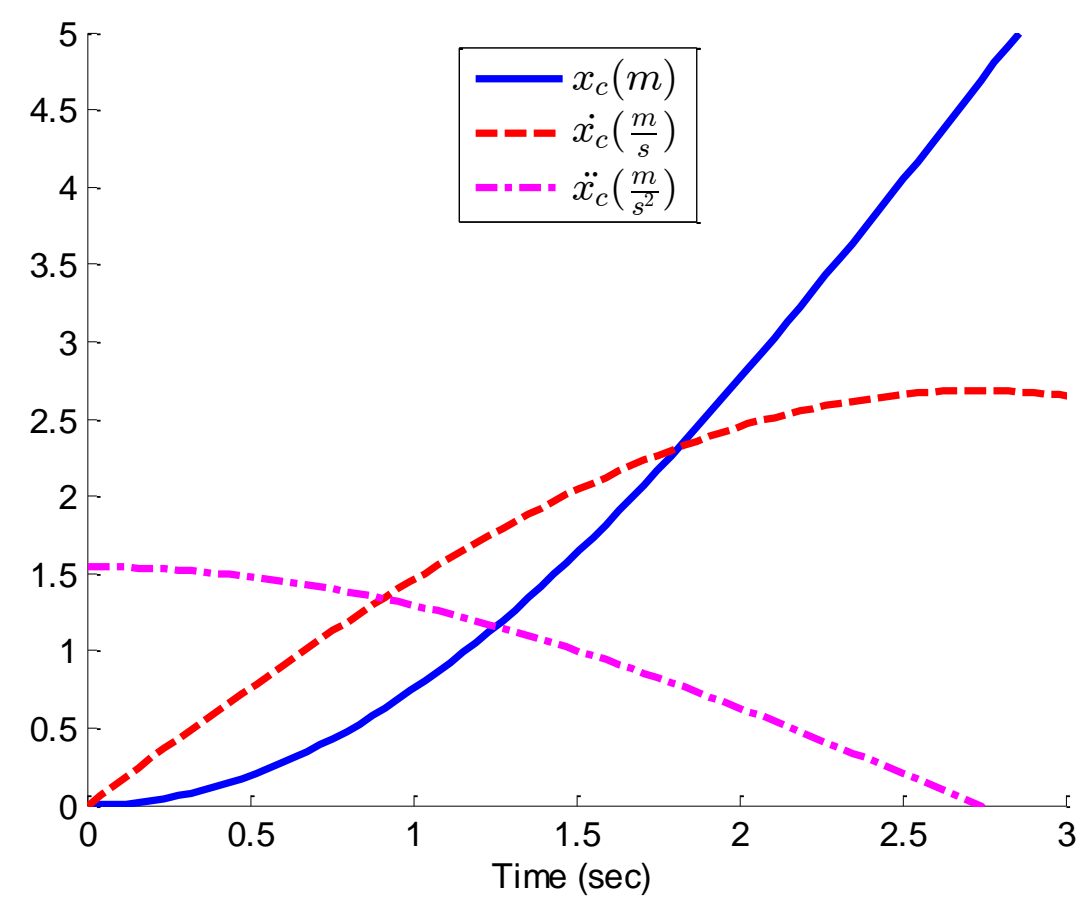

Figure 4.2: Simulation results of the RBLA from Launch Assist beginning at rest with a fully charged spring.

Multiple RBLA configurations were run in the motion study to validate the design equations.

The gear sizes, gear ratio, drum diameter, as well as all of the spring parameters were changed to ensure the formulation was valid. After each configuration was simulated the final velocity, peak acceleration, maximum spring force, distance the vehicle traveled as well as the time of the launch assist were compared to Eqs (3.19), (3.20), (3.16). 
Table 4.1: Launch Assist Simulation Configurations

\begin{tabular}{lcccccccc} 
& $d_{L A}$ & $R_{V}$ & $r_{d}$ & $k$ & $x_{s_{\max }}$ & $N_{a}$ & $d_{s}$ & $D_{s}$ \\
\hline Units & $\mathrm{cm}$ & - & $\mathrm{cm}$ & $\mathrm{N} / \mathrm{mm}$ & $\mathrm{cm}$ & - & $\mathrm{cm}$ & $\mathrm{cm}$ \\
\hline Conf. A & 6.38 & 1.17 & 10.16 & 2.60 & 152.77 & 179.71 & 0.96 & 5.63 \\
\hline Conf. B & 3.18 & 5.00 & 4.91 & 0.61 & 316.76 & 1405.81 & 0.56 & 2.26 \\
\hline
\end{tabular}

Table 4.1 shows two different RBLA's, each design parameter is on the opposing bounds of the device. Each configuration has equal accelerations which propel a vehicle to equal final velocities. These values remain consistent to ensure similar motion results. The large differences between the two RBLA configurations offers verification that each variable is properly accounted for in the formulation, while the final velocity and acceleration remain consistent.

The component sizes in Tab. 4.1 were input into the design modeling equations (Eqs. (3.24), (3.27), (3.28), and (3.29)) in MATLAB to find the expected results. The configurations of the design were simulated using Inventor's Dynamic Simulation environment. The spring was deflected to the maximum length with the vehicle at rest. The spring was then released and the simulation ran until the spring reached its free length.

Both configurations were evaluated to validate the motion equations. The average error for configurations A and B are $1.5 \%$ and $2.2 \%$, respectively. The acceleration term is noted as having the highest error in both configurations. This is due to the fact that the moment of inertia of the entire system was not able to be configured to the exact value used in the design equations. As the moment of inertia has the greatest effect on the acceleration, the acceleration has the highest error. Additionally, the gear ratio has an inverse squared relationship with the moment of inertia. Thus, Conf. B has greater error since the gear ratio is higher. Even-though modeling error exists, it is marginal in both configurations. Thus, the design equations are determined to be validated. 
Table 4.2: Launch Assist Simulation Results

\begin{tabular}{cccccc} 
& $\dot{x}_{c_{\max }}$ & $\ddot{x}_{c_{\max }}$ & $F_{s_{\max }}$ & $x_{c}$ & $t$ \\
\hline Units & $m / s$ & $m / s^{2}$ & $N$ & $c m$ & $s$
\end{tabular}

Conf. A

\begin{tabular}{lccccc}
\hline Motion Eq. & 2.24 & 1.27 & 3964.88 & 393.40 & 2.76 \\
\hline Simulation & 2.28 & 1.31 & 3964.88 & 388.14 & 2.70 \\
\hline Error & $2.1 \%$ & $3.2 \%$ & $0.0 \%$ & $1.3 \%$ & $2.3 \%$
\end{tabular}

Conf. B

\begin{tabular}{lccccc}
\hline Motion Eq. & 2.24 & 1.27 & 1919.50 & 393.40 & 2.76 \\
\hline Simulation & 2.28 & 1.33 & 1919.72 & 394.31 & 2.71 \\
\hline Error & $2.2 \%$ & $4.4 \%$ & $0.0 \%$ & $0.2 \%$ & $2.0 \%$ \\
\hline
\end{tabular}

\subsection{Simulating the EPA Cycle}

The ultimate goal of the RBLA is to increase the fuel efficiency of a vehicle. With the validated design equations and the RBLA correctly simulated, the simulation was taken to a higher fidelity. The consistent test to measure the fuel efficiency of a vehicle in America is to the EPA City Cycle. The EPA City Cycle is a standardized sequence of driving events used to evaluate vehicle fuel consumption. The cycle specifies vehicle speed for each second in time over a 22.8 minute course, simulating urban traffic with many accelerations and decelerations [29]. The driving events include 18 stops, an average speed of $32 \mathrm{~km} / \mathrm{h}$ (20 mph), a top speed of $90 \mathrm{~km} / \mathrm{h}$ (56 mph), encompassing $12.0 \mathrm{~km}(7.45 \mathrm{mi})$ with no elevation changes. The EPA City Cycle speed profile is shown in Fig. 4.3. The velocity profile was entered into the dynamic simulation to find the effect the RBLA has on the vehicle during this cycle, ultimately changing the fuel efficiency. 


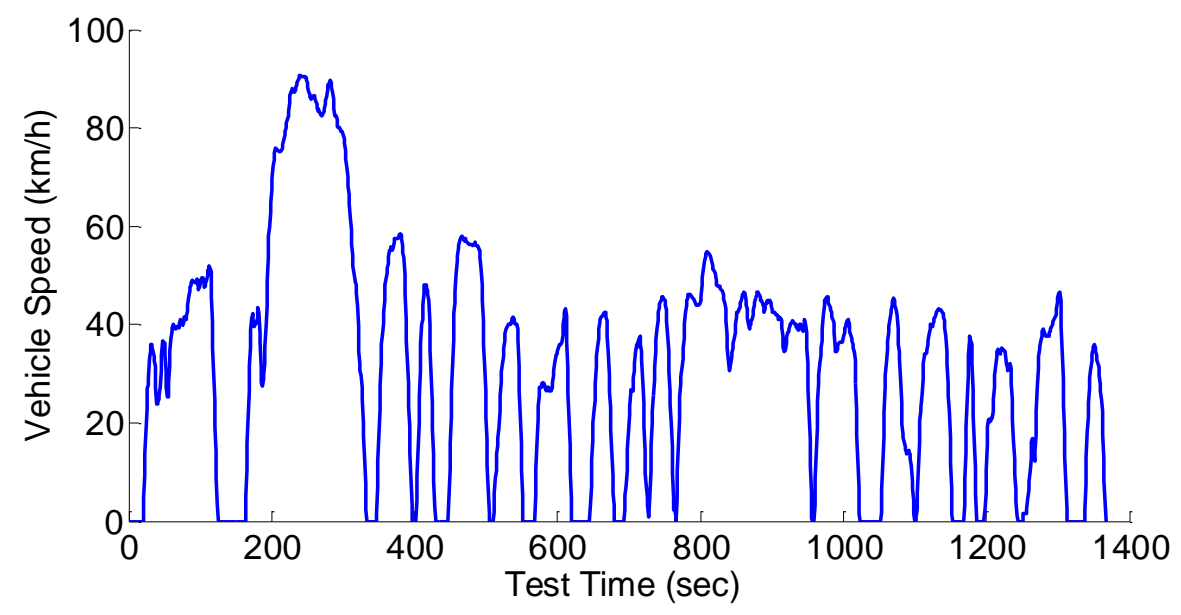

Figure 4.3: The EPA City Cycle velocity profile simulating urban driving.

\subsubsection{Inventor Dynamic Simulation}

The Inventor Dynamic Simulation environment (Inventor) uses an assembly that has been created and replaces the mates with joints (revolute, prismatic, cylindrical, etc.). The software models the force interaction between components and allows user defined motions. Additionally, Inventor allows velocity profiles and logical cases for actions to be executed. This enables the RBLA to operate over the course of the EPA cycle following the logic cues to switch the modes:

I Activate Launch Assist: if the EPA cycle requires acceleration AND if the spring is currently deflected,

II Activate Regenerative Braking: if the EPA cycle requires deceleration AND if the spring is not fully deflected.

First, the velocity profile of the EPA cycle was specified in the software to define the velocity of the road with respect to the RBLA. This was run successfully. 
The launch assist and regenerative braking logic statement were successfully run over the cycle independently. However, it is not a readily available feature in Inventor to allow the deactivation of mates from a logical cue, this is the how the switching of RBLA modes was intended to function. However, Inventor can apply forces and torques from logic cues, which can then be used to simulate such devices as a one-way bearing. However, application of a torque from a logic cue was not functional over the EPA cycle. The current version of Inventor 2013 could not readily simulate the RBLA over the EPA cycle.

\subsubsection{Solidworks Motion Study}

Solidworks Motion Study is similar to the Dynamic Simulation Environment of Inventor but it does not required the conversion of existing mates to joints. Solidworks uses the currently constrained assembly and models force interactions between the components. A preliminary assessment of this software was run simulating the previous RBLA Launch Assist tests. As with Inventor, it found results within $2 \%$. Solidworks has the ability to deactivate mates during a motion study, thus this simulation environment was conjectured to be capable to test the RBLA over the EPA cycle. Solidworks does have similar logic cues for its motion study environment. These, however, can only be used on virtual proximity sensors. The virtual proximity sensors can be used for the spring length, but cannot monitor the acceleration, which would signal when to active the RB or LA clutch. A cue to deactivate a mate cannot be made for acceleration, only for proximity sensors. Thus, Solidworks 2013 was not readily capable to simulate the RBLA over the entire EPA cycle.

\subsubsection{EPA MATLAB Simulation}

Since the two available CAD software packages are not readily capable to simulate the RBLA over the entire EPA cycle it was determined to simulate this method using the design equations in 
MATLAB. The MATLAB simulation evaluates the spring interaction with the vehicle throughout the EPA City Cycle.

The energy stored and subsequently released by the RBLA on the EPA City Cycle is affected by the RBLA design parameters. Each time the vehicle decelerates, energy will be stored in the spring, until the spring is at its maximum deformation, $x_{s}=x_{s \max }$. Likewise, as the vehicle accelerates, energy will be released from the spring until the spring is reduced to its free length, $x_{s}=0$.

For the prescribed EPA Cycle the velocities are given, thus the accelerations and distance traveled are known for each time interval. The distance traveled for a given time interval is directly proportional to the distance the spring moves when the RBLA is activated, as given in Eq. 3.4. Thus, the energy from the RBLA, $E_{L A}$, can be found by modeling the spring deflection over the course of the EPA Cycle, given the above criteria.

At each time increment, the acceleration prescribed from the EPA Cycle, $\ddot{x}_{r_{i}}$, is calculated,

$$
\ddot{x}_{r_{i}}=\frac{\dot{x}_{r_{i}}-\dot{x}_{r_{i-1}}}{t_{i}-t_{i-1}}
$$

as well as the energy to move the vehicle using Eq. (5.3). The previous spring deflection level $x_{s_{i-1}}$ and the acceleration prescribed by the EPA cycle determines which mode should be implemented.

I For any case when the car must decelerate $\left(\ddot{x}_{r_{i}}<0\right)$ and the spring is not currently at its maximum stretched length $\left(x_{s_{i-1}}<x_{s_{\max }}\right)$, the RB mode will be activated. The spring deflection $x_{s_{i}}$ for the interval is,

$$
x_{s_{i}}=x_{s_{i-1}}+\frac{R_{V_{R B}} r_{d}}{r_{w}}\left[\frac{\dot{x}_{r_{i}}+\dot{x}_{r_{i-1}}}{2}\left(t_{i}-t_{i-1}\right)\right]
$$

followed by the deceleration produced from the change in spring deflection $\ddot{x}_{c_{i}}$,

$$
\ddot{x}_{c_{i}}=\frac{-R_{V_{R B}} r_{w} r_{d} k x_{s_{i}}}{J_{R B}+m_{c} r_{w}^{2}}
$$


If the magnitude of the deceleration from the spring is larger than the prescribed deceleration $\left(\left|\ddot{x}_{c_{i}}\right|>\left|\ddot{x}_{r_{i}}\right|\right)$ then the RBLA will be deactivated before the interval is complete. This will lessen the deceleration and only deform the spring to,

$$
x_{s_{i}}=x_{s_{i-1}}+\frac{\dot{x}_{r_{i}}\left(J_{R B}+m_{c} r_{w}^{2}\right)}{R_{V_{R B}} k r_{d} r_{w}} .
$$

In either of the above conditions, if the spring stretch length is above its maximum length it will be set to the maximum length $\left(x_{s_{i}}=x_{s_{\max }}\right)$.

II For any case when the car is accelerating $\left(\ddot{x}_{r_{i}}>0\right)$ and the spring is not currently at its minimum stretched length $\left(x_{s_{i-1}}>0\right)$, the LA mode is activated. The spring deflection for the interval is,

$$
x_{s_{i}}=x_{s_{i-1}}+\frac{R_{V_{L A}} r_{d}}{r_{w}}\left[\frac{\dot{x}_{r_{i}}+\dot{x}_{r_{i-1}}}{2}\left(t_{i}-t_{i-1}\right)\right]
$$

followed by the acceleration produced from the change in spring deflection,

$$
\ddot{x}_{c_{i}}=\frac{R_{V_{L A}} r_{w} r_{d} k x_{s_{i}}}{J_{L A}+m_{c} r_{w}^{2}}
$$

If the acceleration from the spring is larger than the prescribed acceleration $\left(\ddot{x}_{c_{i}}>\ddot{x}_{r_{i}}\right)$ then the RBLA will be deactivated before the interval is complete. This will lessen the acceleration and only deflect the spring to,

$$
x_{s_{i}}=x_{s_{i-1}}-\frac{\ddot{x}_{r_{i}}\left(J_{L A}+m_{c} r_{w}^{2}\right)}{R_{V_{L A}} k r_{d} r_{w}} .
$$

In either of the above conditions, if the spring deflection length is below its minimum length it will be set to the minimum length $\left(x_{s_{i}}=0\right)$.

The energy provided from the spring to accelerate the vehicle is calculated using

$$
E_{L A_{i}}=E_{L A_{i-1}}+\frac{1}{2} m_{c}\left(\dot{x}_{c_{i}}^{2}-\dot{x}_{r_{i-1}}^{2}\right) .
$$


III If neither of these modes are activated the acceleration from the RBLA is set to zero $\left(\ddot{x}_{c_{i}}=0\right)$, and the spring deflection and energy produced from the RBLA remains the same $\left(x_{s_{i}}=x_{s_{i-1}}\right.$ and $\left.E_{L A_{i}}=E_{L A_{i-1}}\right)$.

The RBLA was successfully simulated over the entire EPA City cycle. The energy regenerated then produced from the RBLA was calculated successfully. This method is implemented in an optimization to design the optimal RBLA for a given vehicle, varying each design parameter of the RBLA. 


\section{CHAPTER V}

\section{OPTIMIZATION}

To ideally select the RBLA mechanism design variables, an optimization was preformed using MATLAB's fmincon command. This command minimizes a user-defined multivariable objective function subject to constraints. The ultimate goal of the RBLA device is to improve the fuel efficiency of a vehicle. Accordingly, the fuel efficiency was used as the objective. To create a standard, vehicle-independent measure of the RBLA benefit, the Environment Protection Agency (EPA) City driving cycle was used.

Throughout the optimization, each rotating component in the RBLA was sized and selected, influencing the effective rotational inertia $J_{R B}$ and $J_{L A}$ of the vehicle drivetrain for each mode, RB and LA respectively. Each component is approximated as a steel cylinder, with density $\rho_{s}$. The drum has a width of $w_{d}$ and all gears are considered to have a width of $w_{g}$. The RB input and output gears have diameters of $d_{R B_{1}}$ and $d_{R B_{2}}$. Similarly, the LA input and output gears have diameters

of $d_{L A_{1}}$ and $d_{L A_{2}}$. Additionally, the clutches have inertia of $J_{c l}$ and the vehicle wheels of $J_{w}$. Each component is approximated in the total rotational inertia of the RBLA about the axle

$$
\begin{aligned}
& J_{R B}=\frac{\pi}{32} \rho_{s} w_{g}\left[d_{L A_{1}}^{4}+d_{R B_{2}}^{4}+\frac{\left.d_{R B_{1}}^{4}+d_{L A_{2}}^{4}\right]+\frac{\pi \rho_{s} w_{d} r_{d}^{4}}{2 R_{V_{R B}}^{2}}+2\left(J_{w}+J_{c l}\right),}{R_{V_{R B}}^{2}}\right] \\
& J_{L A}=\frac{\pi}{32} \rho_{s} w_{g}\left[d_{L A_{1}}^{4}+d_{R B_{2}}^{4}+\frac{d_{R B_{1}}^{4}+d_{L A_{2}}^{4}}{R_{V_{L A}}^{2}}\right]+\frac{\pi \rho_{s} w_{d} r_{d}^{4}}{2 R_{V_{L A}}^{2}}+2\left(J_{w}+J_{c l}\right) .
\end{aligned}
$$




\subsection{RBLA Objective Function}

As stated, the EPA City Cycle is used to independently test each vehicle. The vehicle velocity $\dot{x}_{r}$ is specified at each of the 1369 seconds in the profile, the kinetic energy required to complete the course is

$$
E_{r}=\frac{1}{2} m_{c} \sum_{i=1}^{1368}\left[\left(\dot{x}_{r_{i+1}}\right)^{2}-\left(\dot{x}_{r_{i}}\right)^{2}\right] \quad \text { iff } \quad \dot{x}_{r_{i+1}}>\dot{x}_{r_{i}}
$$

which represents each positive acceleration event.

Each negative slope $\left(\dot{x}_{r_{i+1}}<\dot{x}_{r_{i}}\right)$ in the driving cycle represents vehicle deceleration which the kinetic energy is dissipated to the environment through brakes and wasted,

$$
E_{w}=\frac{1}{2} m_{c} \sum_{i=1}^{1368}\left[\left(\dot{x}_{r_{i+1}}\right)^{2}-\left(\dot{x}_{r_{i}}\right)^{2}\right] \quad \text { iff } \quad \dot{x}_{r_{i+1}}<\dot{x}_{r_{i}} .
$$

This energy $E_{w}$ represents the maximum potential savings. With frequent accelerations and decelerations, it is expected that an RBLA installed on a vehicle in this urban setting will have the greatest impact.

Since increases in the speed of the vehicle are a direct result of the energy produced from the engine, that energy is proportional to an amount of gasoline consumed. Each increase in speed produced by the RBLA corresponds to an amount of gasoline saved, since the engine does not need to produce that energy. The increase in fuel efficiency of a RBLA is approximated as Eq. 5.5, where $\eta_{f_{0}}$ is the fuel efficiency of vehicle operating before the installation of an RBLA.

$$
\eta_{f}=\eta_{f_{0}}\left(1+\frac{E_{L A}}{E_{r}}\right)
$$

In addition to the increase in fuel efficiency, the RBLA will also decrease the potential fuel efficiency by adding mass to the vehicle, which can be modeled as payload. Reynolds and Kandlikar quantified a correlation between weight and fuel efficiency for a conventional sedan of approximately $0.7 \mathrm{~L} / 100 \mathrm{~km}$ for each additional $100 \mathrm{~kg}$ of vehicle mass (0.0018-.0040 mpg/lb) [30]. This 
fuel efficiency penalty $\epsilon_{f}$ is multiplied by the weight of the RBLA, $W_{R B L A}$. The weight is estimated assuming all gears, shafts, and springs are made of steel and approximated as a cylinder. Adding this relation to Eq. (5.5), the estimate for fuel efficiency with an installed RBLA is calculated,

$$
\eta_{f_{o b j}}=-\left(\eta_{f_{0}}\left(1+\frac{E_{L A}}{E_{r}}\right)-\epsilon_{f} W_{R B L A}\right)
$$

The EPA cycle is simulated at each iteration, the fuel efficiency of each design is calculated using Eq. 5.6 to find the new fuel efficiency for the vehicle. This equation is the objective of the optimization and is minimized to find the optimal sized RBLA for a vehicle. Note, $\min \left(-\eta_{f_{o b j}}\right)=$ $\max \left(\eta_{f_{o b j}}\right)$.

\subsection{Constraints}

This optimization includes multiple constraining functions. Three equality constraints are used, two ensure the design will propel the vehicle as intended, as represented in Eqs. (3.11) and (3.19). The final equality ensures the spring will meet the desired stiffness given in Eq. (3.28).

Inequality constraints are also implemented for reliability. The spring will encounter cyclical stress loading as given in Eq. (3.29). This will be limited to acceptable endurance stress limits for

spring steel, $\tau_{\max } \leq 500 \mathrm{MPa}$ (75 ksi) [31]. To facilitate manufacturing, the spring index $C$ is constrained to

$$
4 \leq C \leq 12
$$

Additionally, an inequality is implemented to prevent interference. The center distance between the axle and countershaft is $\left(d_{L A_{2}}+d_{L A_{1}}\right) / 2$. To ensure that the drum and axle have at least a clearance of $d_{g}$

$$
\frac{1}{2}\left(d_{L A_{1}}+d_{L A_{2}}\right)-r_{a x}-r_{d} \geq d_{g}
$$


where $r_{a x}$ is the radius of the axle. This inequality is also implemented for the RB gear train, substituting $d_{R B_{1}}+d_{R B_{2}}$ for $d_{L A_{1}}+d_{L A_{2}}$, respectively. It is assumed that only one center distance will define the distance between shafts, the other gear train will have a belt, chain, or idler.

Finally, to ensure the maximum comfortable acceleration and deceleration is achieved for both configurations [21], Eq. (3.20) is the final inequality constraint which is used for both gear ratios, $R_{V_{L A}}$ and $R_{V_{R B}}$.

In addition to the constraints, bounds are placed on each design variable as shown in Table 5.1. Each variable was assigned upper and lower bounds constraining it due to practicality, safety, or manufacturability. For example, the acceleration had an upper bound of $0.25 \mathrm{~g}$ since this is the maximum comfortable acceleration for a user in an automobile [21]. Spring variables were limited to practicality and manufacturability. For example, the total length of the spring $l_{s}=N_{d} d_{s}+x_{s_{\max }}$ is limited proportionally by the length of the vehicle.

Table 5.1: Optimization parameters

\begin{tabular}{lcccccc} 
& $\ddot{x}_{c_{\max }}$ & $d_{L A}$ & $R_{V_{L A}}$ & $d_{R B}$ & $R_{V_{R B}}$ & $r_{d}$ \\
\hline Units & $\mathrm{m} / \mathrm{s}^{2}$ & $\mathrm{~cm}$ & - & $\mathrm{cm}$ & - & $\mathrm{cm}$ \\
\hline Lower Bound & 1.3 & 5.08 & 0.10 & 5.08 & 0.10 & 2.54 \\
\hline Upper Bound & 2.4 & 15.24 & 10.00 & 15.24 & 10.00 & 15.24 \\
\hline Sedan & 2.4 & 9.29 & 0.16 & 5.08 & 0.28 & 2.54 \\
\hline
\end{tabular}

\begin{tabular}{lccccc} 
& $x_{s_{\max }}$ & $l_{s}$ & $d_{s}$ & $D_{s}$ & $k$ \\
\hline Units & $\mathrm{cm}$ & $\mathrm{cm}$ & $\mathrm{cm}$ & $\mathrm{cm}$ & $\mathrm{kg} / \mathrm{cm}$ \\
\hline Lower Bound & 7.6 & 12.7 & 0.08 & 0.12 & 5.8 \\
\hline Upper Bound & 330.2 & 431.8 & 2.03 & 9.60 & 230.4 \\
\hline Sedan & 127.4 & 223.8 & 2.03 & 8.13 & 192.2 \\
\hline
\end{tabular}


The completed optimization function will output all the design variables as well as size all of the components of the RBLA. The clutch, gears, spring, and drum are sized and selected.

\subsection{Optimization Results}

A conventional sedan was modeled and found an $8.4 \%$ increase in the fuel efficiency for this vehicle after an optimally designed RBLA with a steel extension spring was installed. The fuel efficiency increased from 27.4 city mpg $(8.71 / 100 \mathrm{~km})$ to over $29.7 \mathrm{mpg}(9.4 \mathrm{l} / 100 \mathrm{~km})$ in the city.

It is worth noting, the RBLA will quickly charge and discharge the spring while in use. The spring length changes many times, some instances it will deform its entire length in as little as 3 seconds, as seen in Figs. 5.1 and 5.2. The feasibility of a spring's durability during this rigorous event requires future research.

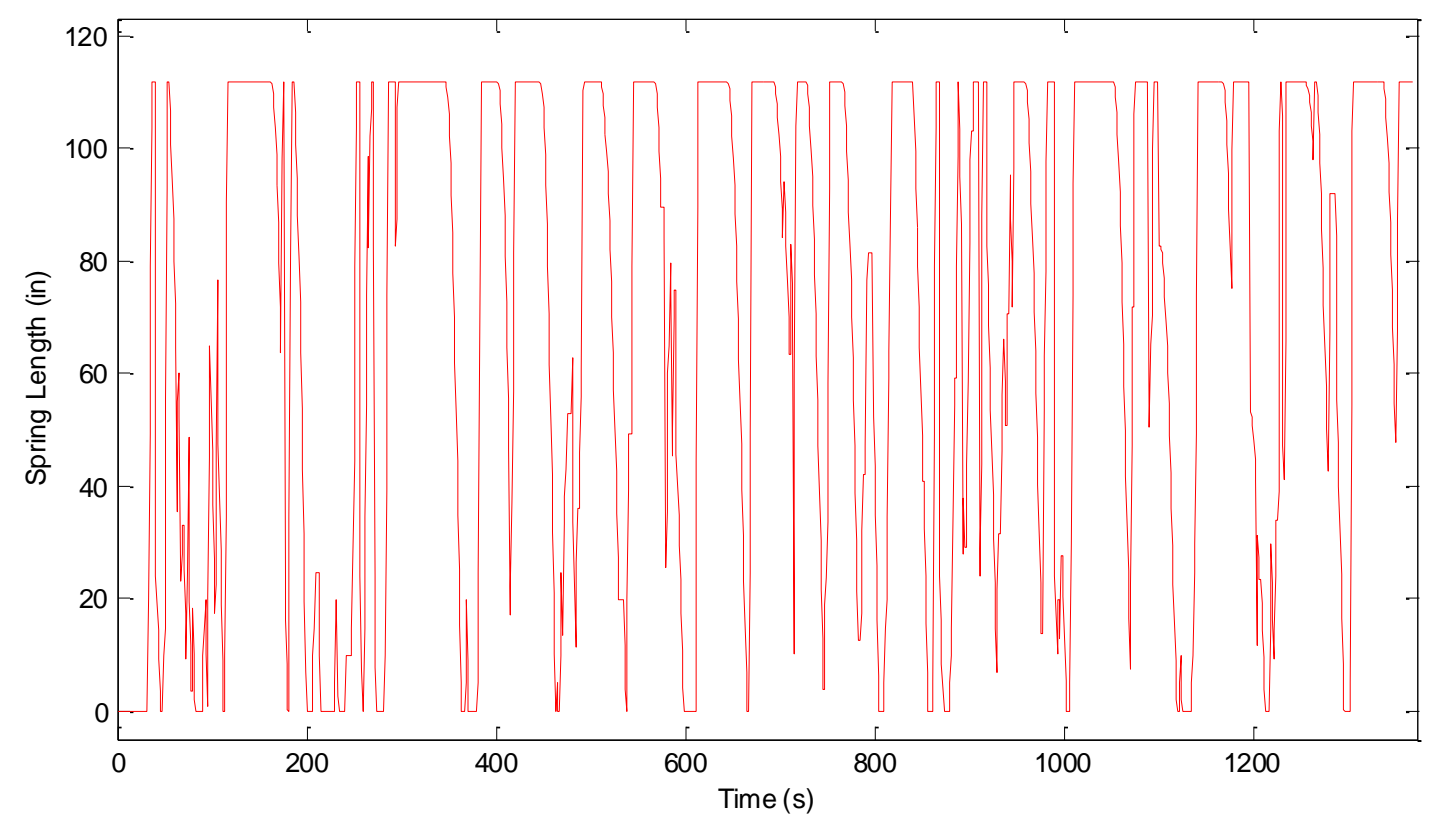

Figure 5.1: Spring deflection over the course of the EPA City Cycle. 


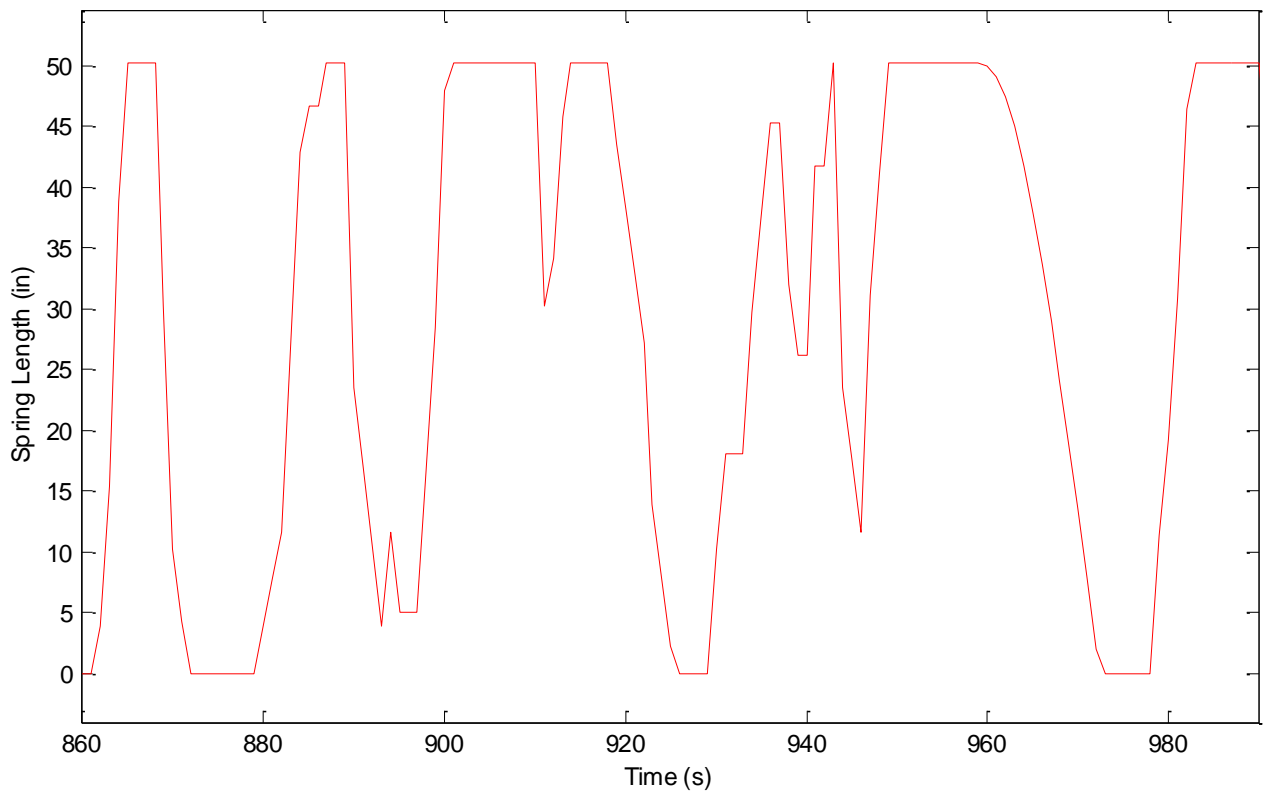

Figure 5.2: Spring deflection during a two minute portion of the EPA Cycle. 


\section{CHAPTER VI}

\section{BENCHTOP PROTOTYPE}

\subsection{Prototype Design}

A benchtop prototype was designed to test the RBLA concept. The goal for this prototype is to validate the concept, find the amount of slip when actuating clutches, and find the efficiency of the system. The device must be small enough to fit on top of a benchtop in the DIMLab, easily actuated by an operator, durable for use in future demonstrations, as well as remain safe enough so it will not need to be encased in protective barriers. Since the device will remain stationary, a flywheel is implemented to simulate the torque from the car tire and the acceleration of the vehicle mass. The spring is downsized to fit on a table as well as to limit the maximum speed of the flywheel to under $500 \mathrm{rpm}$ (for safety). Finally, a different type of clutch is used in the prototype than would be used in the full scale RBLA for the size and ease of actuation.

\subsubsection{Prototype Clutches}

The smallest stock automotive drivetrain clutch readily available (7 in.) is still greatly oversized for this benchtop application. The 7 in. automotive drivetrain clutch was purchased and tested to find the throwout force. A diaphragm clutch, such as the automotive drivetrain clutch, uses a diaphragm spring to supply the normal force to engage the clutch. To disengage the clutch, a force must be applied (the throwout force) to counteract the spring. For the benchtop prototype this is the 
force the user will supply to actuate the RBLA. Initially, it was estimated the force required would be $400 \mathrm{lb}$ for the purchased clutch. This was later confirmed upon testing using a force gauge and arbor press. One way to reduce the throwout force is to cut the diaphragm. Changing the diaphragm from a solid circle to a $\mathrm{C}$ shape reduces the strength of the diaphragm, thus reducing the throwout force. This also reduces the maximum torque the clutch can retain, yet this is oversized for this application. Upon completion the throwout force reduced from $400 \mathrm{lb}$ to $300 \mathrm{lb}$, a force still too large for a benchtop model. A force this large could be actuated with the use of levers, yet the structure of the prototype would need to be able to hold this excess force. It was decided automotive drivetrain clutches were not feasible for the benchtop size.

Automotive air-conditioner (A/C) clutches are electrically actuated and are roughly 5 inches in diameter. They use a coil to produce a magnetic field, pulling the clutch plates together. This clutch is small enough to be used on a benchtop prototype but still strong enough not to limit the spring size. Two clutches were purchased and installed on the prototype. These clutches require $12 \mathrm{~V}$ and 4 Amps when the clutch is engaged, this is the main reason they were not considered for the full-scale RBLA concept. Additionally, these clutches have serpentine belt grooves machined into the sides. Since the clutches were designed for use with belts, the idler gear was replaced with a belt reducing the RBLA to a one plane structure.

The $\mathrm{A} / \mathrm{C}$ clutches did not provide a rated torque, thus they were tested to find the slip torque. When the LA clutch is engaged and the pawl is released the torque will change from the minimum to maximum in a fraction of a second. For this reason it was decided to test an impulse torque on the clutch. The clutch was locked into a vice and engaged. A force gauge was attached to the clutch surface at a known distance and an impulse force was applied repeatedly until the clutch slipped. The force on the force gauge was noted each time the clutch slipped. The A/C clutches were tested to find an impulse slip-torque of $30 \mathrm{ft}-\mathrm{lb}$. 
It is assumed the prototype clutch will have similar losses to the full sized RBLA clutch. The clutch in the RBLA is designed to be fully engaged or fully disengaged. The losses due to the clutch occur when the clutch is engaging during regenerative braking. Since the two shafts are spinning at different speeds the clutch will slip until both shafts reach the same speed reducing the maximum energy storage. The clutch is sized to limit the slip. The maximum torque produced from the spring will not surpass the rated torque of the clutch. Thus, the clutch will not slip during launch assist unless the pawl is released early. The prototype spring was estimated to propel the axle to over 300 rpm, using Eqns. (3.22) and (3.24). This rotational speed is similar to a vehicle moving $50-65 \mathrm{~km} / \mathrm{h}$ (30-40 mph) depending on the tire size. This large speed should aid in the estimation for the amount of energy lost due to clutch slip for the proposed RBLA.

\subsubsection{Prototype Sizing}

Serpentine belts are common for vehicles, however sizes are often much larger than this application requires $(4-5 \mathrm{ft})$. A 26.4 in. $(10.4 \mathrm{~cm})$ belt was identified, which defined the center distance between shafts. This center distance determined the gear sizes: 6 in. $(15 \mathrm{~cm})$ and 4.8 in. (12.2 $\mathrm{cm}), 20^{\circ}$ gears. With all major components defined, the remainder of the parts were sized based on geometry and availability, not performance. For example, the flywheel was chosen as a vehicle brake rotor for its concentricity and balance; its weight and moment of inertia were not considered for its selection.

The prototype design has two shafts that share an axis, the main shaft and a floating shaft which is on bearings around the main shaft. The dual shafts have a similar design to clocks or jet engines. The main shaft diameter was determined from the clutch size. The internal diameter of the clutch has a tube, the floating shaft, inserted with bearings pressed in place. The internal diameter of that bearing sized both shafts. The floating shaft connects the floating side of the clutch to the gear. The coil of the clutch does not rotate thus it was placed on a second bearing, with the inside race on the 
floating shaft tube, Fig. 6.1. The outer race determined the coil mount diameter, which was fixed to the structure for both clutches.

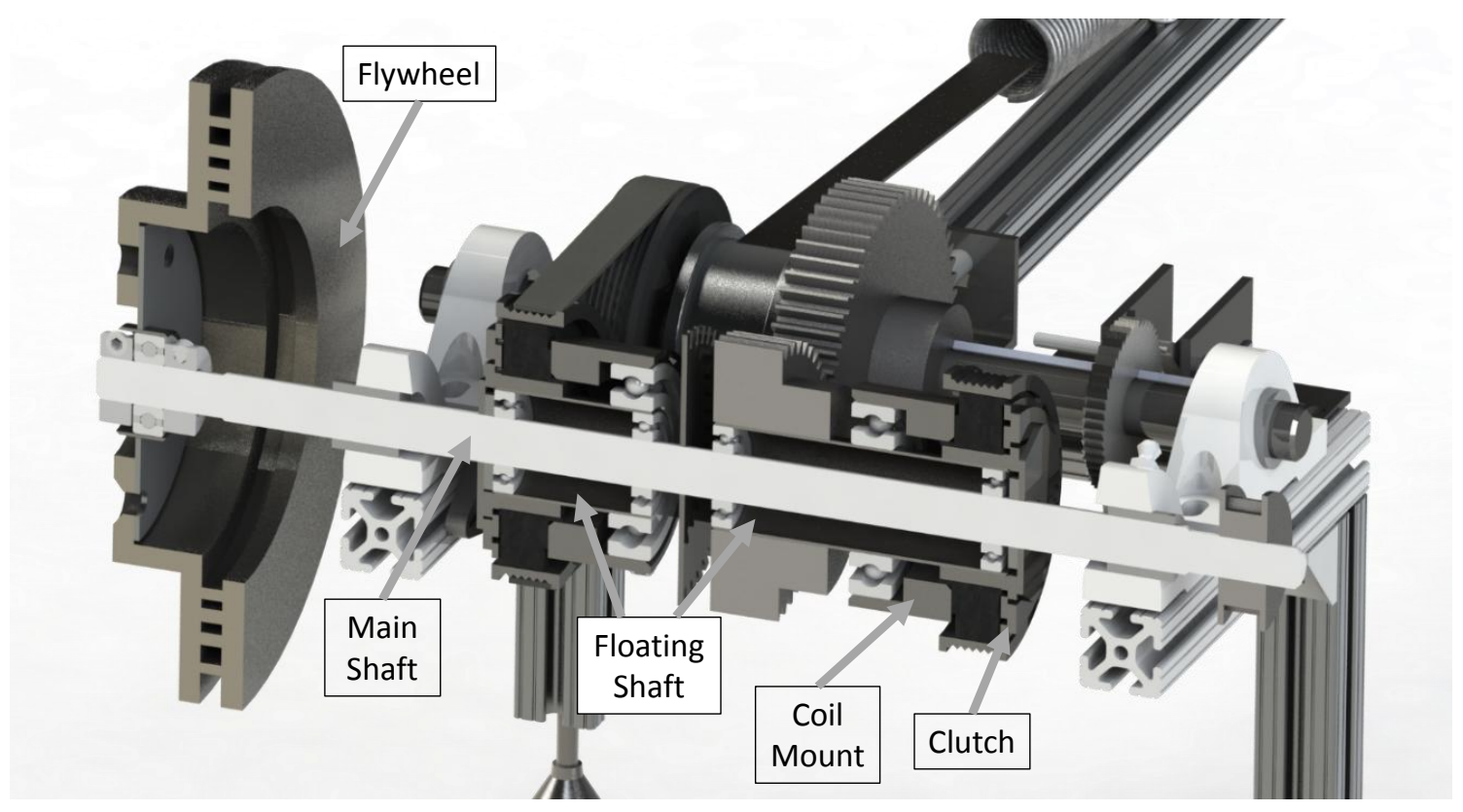

Figure 6.1: A rendered section view of the prototype main shaft showing the floating shaft and all other components.

The spring was selected to keep the maximum rotation speed of the flywheel under $500 \mathrm{rpm}$. Additionally, as the total spring length reduces, so will the footprint of the device. A spring was selected with a free length $x_{s_{o}}=9$ in. $(23 \mathrm{~cm})$, spring deflection $x_{s_{\max }}=8$ in. $(20 \mathrm{~cm})$, mean coil diameter $D_{s}=2$ in. $(5.1 \mathrm{~cm})$, wire diameter $d_{s}=0.2$ in. $(0.51 \mathrm{~cm})$, and a stiffness $k=17.9 \mathrm{lbf} / \mathrm{in}$ $(20.6 \mathrm{~kg} / \mathrm{cm})$.

\subsection{Experimental Evaluation}

The prototype was initially tested to prove the functionality of the concept. The RB mode was activated, energy was stored in the spring, then the LA mode was activated. The pawl was released 


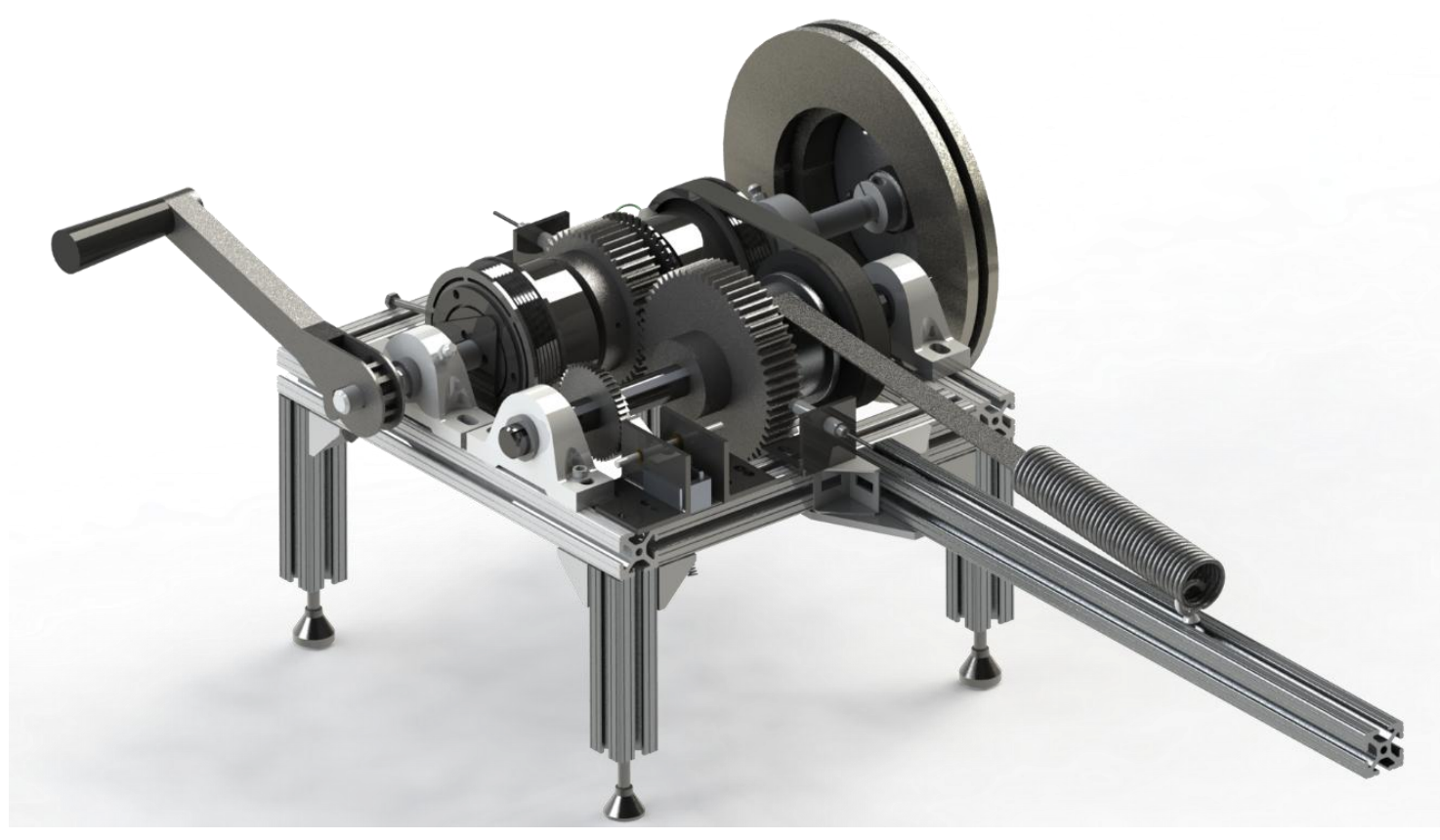

Figure 6.2: Rendered image of the completed benchtop prototype.

and the flywheel quickly accelerated. The prototype functioned as intended. Future work will study the efficiency of the system, losses due to the spring, and the clutch slippage. A test plan for that work is provided below.

\subsubsection{Sensors}

The goal for this prototype is to find the efficiency and losses of the system. Possible losses may occur within the spring or when the clutches slip. By monitoring the speed of both shafts and the spring force, the energy may be approximated at each instance.

Monitoring the speeds of both shafts, with a known gear ratio, will show any slip due to the clutches. Both shafts should accelerate with the same velocity ratio, thus if there is any difference in the velocity ratio, slip has occurred. Proximity sensors were chosen to monitor the shaft speeds. One sensor is placed facing the gear on the counter shaft, using the teeth to monitor the speed. The 


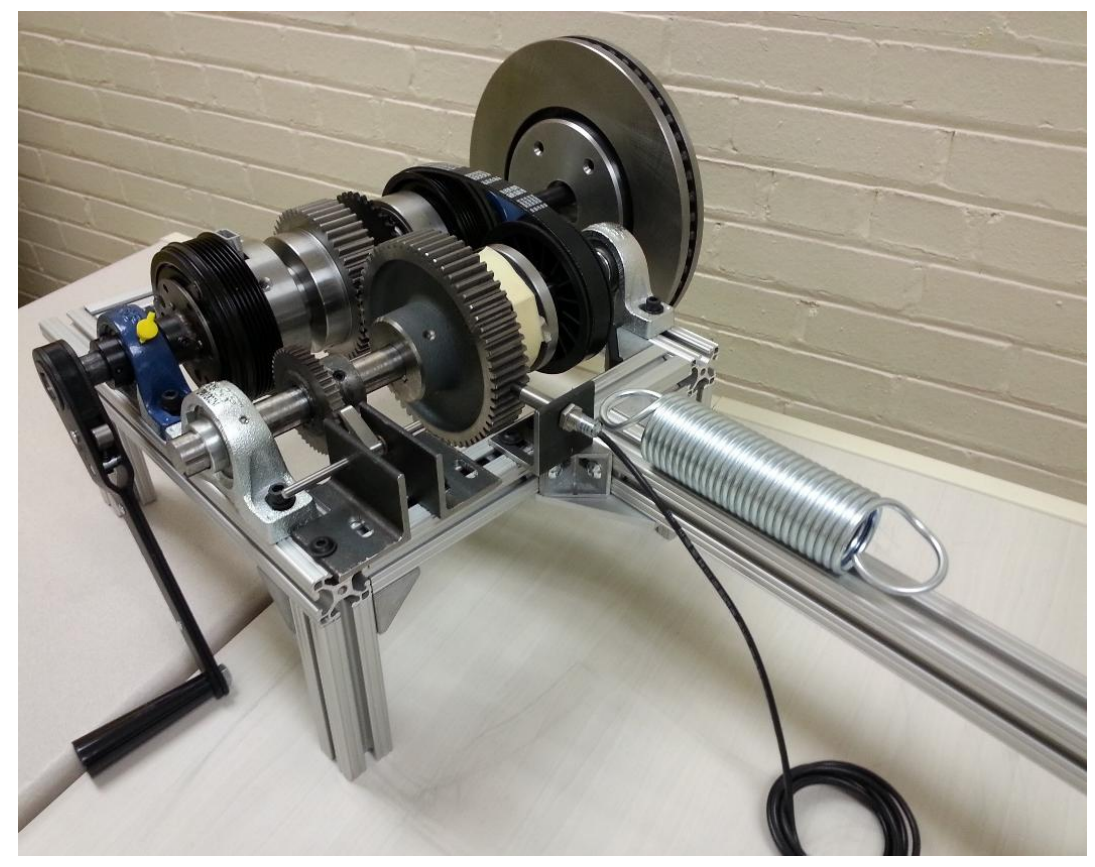

Figure 6.3: The completed benchtop prototype.

second proximity sensor was placed facing a sprocket fixed to the axle shaft. A strain gauge was implemented inline with the spring to determine the strain force stored in the spring.

\subsubsection{Test Plan}

In the initial condition the spring will be stretched to its maximum length. Then the launch assist clutch will be engaged and the spring released. Encoders will monitor the speeds of both shafts to monitor the slipping of the clutches. Once the spring is at its free length and the flywheel has reached its maximum speed, the regenerative braking clutch will be actuated. The flywheel will decelerate and the spring will extend. The stored energy in the spring will then be noted to find the loss from the system. Then the prototype will be cycled between launch assist and regenerative braking multiple times. This test estimates the losses due to spring storage, clutch slip, and the efficiency of the entire system. 


\subsubsection{Prototype Observations}

There are losses in this prototype due to part and fabrication quality. Two bearings do not preform to specification; they do not move smoothly. In addition, one gear bore was increased, yet the new hole is slightly eccentric to the gear. The losses due to the quality of this prototype would not exist for a production RBLA, the components would have higher quality. The efficiency results of the entire prototype, at its current state, are no longer viable to be extrapolated to the full-sized RBLA. The testing will focus on the slip and amount of energy lost during slip.

The spring selected was chosen for its high stiffness and short length, to propel the flywheel to high speeds while reducing the footprint of the prototype. However, a longer spring with a smaller stiffness is desired for testing since the current spring releases all its energy in approximately 1 second. Additionally, since the spring releases so rapidly it is difficult to manually deactivate the LA mode and activate the RB mode while the flywheel is still in motion. A longer release, reducing the acceleration, is better suited for testing. This could achieved by reducing the gear ratio, drum diameter, or the spring stiffness, as seen in Eq. (3.27). 


\section{CHAPTER VII}

\section{CONCLUSION AND FUTURE WORK}

\subsection{Conclusion}

This thesis presented the research leading to the design of a spring based RBLA. For the RBLA to have the greatest effect on a vehicle the design was optimized. The device's effect on the vehicle was assessed by the physics of defining the system. Design equations, which modeled the motion of the device and the strain of the spring, were validated by dynamic simulations. The design equations were also used to optimize and size the design. Finally, the optimized design was simulated to validate the device and find its true effect on the vehicle. Initial projections state the RBLA can improve the fuel efficiency of a consumer sedan by over $8 \%$.

\subsubsection{Concept Design}

The device is intended to be installed on the non-drive axle of the vehicle. Springs deflect in one direction for storage then the opposing direction to release energy. The vehicle requires only forward motion, thus the RBLA must account for this reversal in direction. Additionally, the system will only be active for regenerating while braking, and launching during an acceleration. Thus it must disengage from the vehicle to minimize the affect on the overall performance of the vehicle. These requirements drove the design of the RBLA concept. 
The RBLA has three modes: regenerative braking, launch assist, and idle. Regenerative braking converts the vehicle's kinetic energy and stores it in the spring. Launch assist releases the stored spring energy to propel the vehicle. Idle disengages the entire RBLA retaining the stored energy, if any, while minimizing the affect on the performance of the vehicle.

The design concept requires a counter shaft to be installed on the vehicle parallel to the nondrive axle. This shaft is connected to the axle by two gear trains. One gear train implements a reversal in direction ny using a belt, chain, or idler. Each gear on the axle has a bearing pressed into its bore and a clutch surface on one side. The gears on the axle do not rotate with the axle. Two clutches, one paired with each gear mounted to the axle, are fixed to the axle. When each clutch is activated, the corresponding gear train will rotate with the axle, transferring torque to the counter shaft. The spring is mounted to the counter shaft, storing and releasing the torque from the gear trains. Finally, a pawl and ratchet is implemented to maintain the stored energy within the spring while allowing both clutches to deactivate. This reduces the impact on the vehicle when the RBLA is not in use.

Steel extension springs were chosen for the initial use in this application. Current research comparing spring types is being conducted by the research lab, thus the design has been configured to adapt to each spring type (extension, torsion, leaf, etc.).

Clutches were chosen to engage and disengage the RBLA to the axle. Clutches have the ability to bring two rotating bodies to the same speed quickly and effectively, which is why they were chosen.

\subsubsection{Design Equations}

The RBLA was modeled to predict its effect on a vehicle. The system included the weight, motion, and drag of the vehicle, the rotational inertia of the RBLA and axle, the torque applied from 
the RBLA, as well as the defining equations of the spring. These dynamic equations were combined to model the RBLA's effect on the motion of the vehicle while sizing each component of the RBLA and the spring.

The design equations were compared to a dynamic simulation, which modeled each RBLA component and its effect on the motion of the vehicle. The dynamic simulation was run in multiple configurations, with different sized components for both the RB and LA modes. Results were within $2 \%$ of the design equations, thus the simulation validated the design equations.

\subsubsection{Optimization}

For the RBLA to have the greatest effect on a vehicle, the design was optimized. Each component of the RBLA was sized implementing the design equations into an optimization in MATLAB. For a standard, vehicle-independent study of the RBLA over driving conditions, the RBLA was modeled on the EPA City Cycle. This standard test is used for each vehicle in the US, which models many accelerations and decelerations over a 22 minute, $7.5 \mathrm{mi}$ cycle to simulate urban driving. The RBLA was modeled over each second of the EPA cycle by activating the RB or LA modes during an acceleration or deceleration, accounting for the spring deflection and the required acceleration at each step. Each time the spring energy was used to propel the vehicle, that kinetic energy was noted to find the total energy produced from the RBLA. The RBLA energy was then compared to the total kinetic energy to complete the entire EPA cycle to account for the energy savings. Additionally, the negative effect on fuel efficiency from the extra weight of the RBLA was removed from the energy savings and a new fuel efficiency was found. MATLAB's fmincon command was used to size each component of the RBLA, with the objective to maximize the new fuel efficiency produced from the RBLA. 
The RBLA was optimized over the EPA cycle for an average consumer sedan. The RBLA was designed with a spring that is $7.4 \mathrm{ft}$. long, $2.4 \mathrm{in}$. mean diameter with a wire size of $0.8 \mathrm{in}$. The ideal RBLA increased a $2000 \mathrm{lb}$ sedan from $27.4 \mathrm{mpg}$ to $29.7 \mathrm{mpg}$, which is a $8.4 \%$ increase in savings. However, this is an ideal model with no friction, drag, clutch slip or other types of losses.

\subsubsection{Prototype and Testing}

A benchtop prototype was designed with the primary goal to validate the functionality of the concept. Upon completion of the prototype, the system operated successfully which validated the functionality. Future work will test this device to find efficiencies, losses due to clutch slip as well as other losses and use those results to extrapolate the RBLA effect with losses.

\subsection{Future Work}

Over the course of this research, potential improvements were found which were not able to be implemented. A summary of those improvements with recommendations are listed below.

\subsubsection{EPA Simulation}

Solidworks 2013 and Inventor 2013 dynamic simulation environments were not readily able to test the RBLA device over the course of the entire EPA cycle. Two other programs may make it possible for future work to model the EPA cycle. Adams is a dynamic simulation software by MSC that should be able to run this study, since it has expansions for controls. At the time this software could not be attained, but it has recently been made available to students.

Additionally, ADVISOR, a MATLAB program sponsored by the Department of Energy, has the ability to model a regenerative braking device on various vehicles over the course of a predetermined cycle. Upon initial assessment it was determined the creation of original software to model this is 
more reliable. Yet, this software models many sub-components within the vehicle and could bring a higher fidelity to the model [28].

\subsubsection{Increase Fidelity of the Optimization}

The objective function models the vehicle across the entire EPA city cycle then assumes the total energy consumed is directly proportional to the fuel efficiency, since the EPA city cycle is a fixed distance at given speed intervals. However, the fuel efficiency of a vehicle is not constant. The fuel efficiency can change due to the engine power and the output speed of the engine, as seen in Fig. $7.1[3]$.

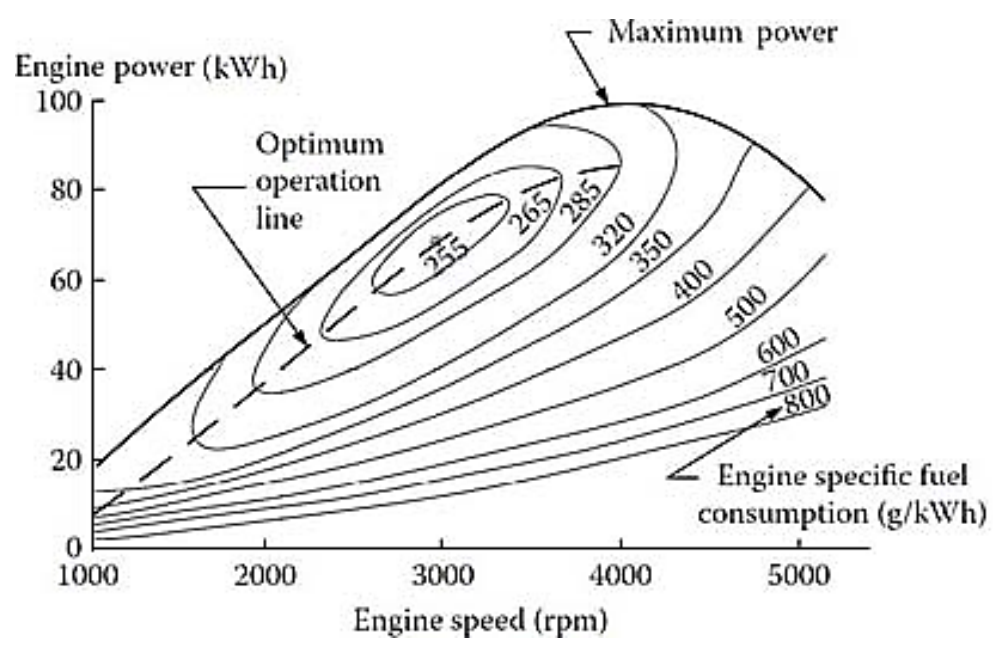

Figure 7.1: Specific Fuel Consumption at various engine speeds and energy outputs [3].

The fuel efficiency at lower speeds is worse than the efficiency at moderate and high speeds for a vehicle. The LA mode is often activated during low speeds, during the poor fuel efficiency stages. The RBLA will reduce the engine use in the low efficiency stages, increasing the total potential savings. An increased level of fidelity of the optimization would implement this relation between 
fuel efficiency and vehicle speed in the objective function. Accounting for the fuel efficiency each time the LA mode is activated should increase the performance of the RBLA.

The optimization function, since it finds the optimal energy to weight ratio of the spring, outputs extension springs with thick wire, approximately $2 \mathrm{~cm}(0.8 \mathrm{in}$.$) , and maximizes the length of the$ spring extension. This wire is similar to the thickness to the shock absorbers in trucks and SUV's. The total extended spring length limit has a high effect on the performance of the RBLA. Further research will be implemented to find the longest spring that will fit in an existing vehicle, which will increase the performance of the RBLA. Possible devices will contain cables and pulleys to increase the total possible stretched distance.

Current research is investigating the optimal spring type (torsional, extension, leaf, etc.) to be implemented by the RBLA. An extension spring was initially chosen, yet this device can function using types of springs. It is possible the type of spring can differ between vehicles (ie. extension is better for one vehicle while torsion is better for others). The integration of spring type selection into the optimization, increases the fidelity of the optimization.

Additionally, the effect of the weight of the RBLA on the vehicle fuel efficiency uses the relation from Reynolds and Kandlikar, yet this is only for sedans with moderate amounts of additional payload. Further research must be completed to apply the RBLA to trucks, trains, buses, planes, and other vehicles.

\subsubsection{Prototype Automation}

Future work will cover the testing of the prototype to find the efficiencies and losses of the system, as mentioned in Section 6.2. Additionally, the automation of the prototype will increase the quality of these tests. Currently the prototype requires the operator to manually disengage and engage each clutch as well as release the pawl. However, a basic controller can be developed to 
automate this design. A strain gage can monitor the energy of the spring, thus it will monitor when the spring is at its maximum or minimum energy level. The current encoders produce the shaft speeds which will be monitored to find the when the axle changes from acceleration to deceleration.

The spring will be initially stretched to its maximum length by the operator. Then the automation may begin. First, the LA clutch will be engaged and the pawl will be released. The strain gauge will monitor when the spring reaches its minimum energy level (which is slightly larger than its free length). At that point the LA clutch will be disengaged, the RB clutch will be engaged and the pawl will be engaged (which will be overrun while regenerating). The encoder on the main shaft will begin this cycle again once the main shaft becomes static and all the energy is stored in the spring.

This automation should increase the efficiency of the prototype, since the efficiency measures the initial energy to the regenerated energy. All of the necessary components are currently in place. Additionally, if slippage does often occur the washers between the clutch and the coil can be reduced in thickness to increase the clutch force.

Additionally, a motor could be added to the prototype main shaft to simulate the vehicle engine. A scaled version of the EPA cycle could be run with the automated RBLA. This scenario would be able to not only test the controls, but additionally find the savings over a given cycle such as the EPA.

\subsubsection{Controls}

While charging or discharging, the spring will be constantly changing level of deformation, thus the torque affecting the vehicle acceleration will also change. The initial intent is for the RBLA to be activated with a small press of either pedal. If the pedal is depressed further the engine/brakes will active simultaneously with the RBLA. The small depress of the pedal is used assuming the RBLA will not define the acceleration of the vehicle but simply aid it. However, if the RBLA is 
close to maximum capacity the acceleration will be close to $0.25 \mathrm{~g}$, which may be higher than the acceleration normally attributed with a small depress. More research into the relationship between energy level of the RBLA and the location of activation with respect to the pedal actuation will be studied. Possible methods may include different activation zones over the pedal motion while the RBLA is at low energy and high energy.

\subsubsection{Clutch Slip}

The RBLA will lose energy due to clutch slip, the main concern is during the LA mode. If the spring is released and the clutch slips, an unknown amount of energy will be lost. The prototype will be tested to find the amount of slip, however this cannot be accurately scaled to the full size RBLA. Clutch slip can be modeled but the clutch must first be designed or selected. Many parameters are unknown at the current level of detail. Once a clutch is determined, the slip can be modeled with Simulink using methods by Dassen or Garofalo [26, 32]. 


\section{BIBLIOGRAPHY}

[1] S. Evans, "Volvo S60 flywheel KERS prototype first drive," Motor Trend, July 2013.

[2] M. EauClaire, "Joining forces," OEM Off-Highway, vol. 23, pp. 40-47, 2008.

[3] M. Ben-Chaim, E. Shmerling, and A. Kuperman, "Analytic modeling of vehicle fuel consumption," Energies, vol. 6, no. 1, pp. 117-127, 2013.

[4] K. A. Small and K. Van Dender, "Fuel efficiency and motor vehicle travel: the declining rebound effect," The Energy Journal, pp. 25-51, 2007.

[5] I. Husain, "Electric and hybrid vehicles: Design fundamentals," 2011.

[6] S. Carothers and A. Hurt, "Map: Hybrid and electric sales across the country," November 2011.

[7] S. A. Oleksowicz, K. J. Burnham, A. Southgate, C. McCoy, G. Waite, G. Hardwick, C. Harrington, and R. McMurran, "Regenerative braking strategies, vehicle safety and stability control systems: critical use-case proposals," Vehicle System Dynamics, vol. 51, no. 5, pp. 684699, 2013.

[8] M. Guarnieri, "When cars went electric, part one [historical]," Industrial Electronics Magazine, IEEE, vol. 5, no. 1, pp. 61-62, 2011.

[9] I. Arsie, M. Graziosi, C. Pianese, G. Rizzo, and M. Sorrentino, "Optimization of supervisory control strategy for parallel hybrid vehicle with provisional load estimate," Proc. of AVEC04, pp. 23-27, 2004.

[10] D. Cross and C. Brockbank, "Mechanical hybrid system comprising a flywheel and CVT for motorsport and mainstream automotive applications," SAE Technical Paper, pp. 01-1312, 2009.

[11] F. Bottiglione, G. Carbone, L. D. Novellis, L. Mangialardi, and G. Mantriota, "Mechanical hybrid KERS based on toroidal traction drives: An example of smart tribological design to improve terrestrial vehicle performance," Advances in Tribology, no. 9, 2013. 
[12] S. Maeda and M. Morioka, "Measurement of whole-body vibration exposure from garbage trucks," Journal of Sound and Vibration, vol. 215, no. 4, pp. 959-964, 1998.

[13] G. J. Heydinger, R. A. Bixel, W. R. Garrott, M. Pyne, J. G. Howe, and D. A. Guenther, "Measured vehicle inertial parameters-NHTSA's data through november 1998," SAE transactions, vol. 108, no. 6; PART 2, pp. 2462-2485, 2000.

[14] P. Weissler, "Mazda introduces supercapacitor-type regenerative braking," SAE International, 2013.

[15] L. Hoppie, "The use of elastomers in regenerative braking systems," Rubber Chemistry and Technology, vol. 55, no. 1, pp. 219-232, 1982.

[16] L. O. Hoppie and D. Speranza, "Prestressed elastomer for energy storage," Jun. 8 1982, US Patent 4,333,553.

[17] L. O. Hoppie, "Regenerative braking device with rotationally mounted energy storage means," Mar. 16 1982, US Patent 4,319,655.

[18] M. F. Ashby, "Materials selection in mechanical design," MRS BULLETIN, vol. 30, p. 995, 2005.

[19] C. Silva, M. Ross, and T. Farias, "Analysis and simulation of low-cost strategies to reduce fuel consumption and emissions in conventional gasoline light-duty vehicles," Energy Conversion and Management, vol. 50, no. 2, pp. 215-222, 2009.

[20] Y. Gao and M. Ehsani, "Electronic braking system of EV and HEV-integration of regenerative braking, automatic braking force control and ABS," SAE Technical Paper, 2001.

[21] J. Gebhard, "Acceleration and comfort in public ground transportation,” 1970.

[22] M. F. Spotts, T. E. Shoup, L. E. Hornberger, Y. Liu, and W. Li, Design of machine elements. Pearson/Prentice Hall, 2004.

[23] J. Budynas, R. Nisbett, Shigley's Mechanical Engineering Design, 9th ed. McGraw-Hill Publishing Company, New York, 2010.

[24] F. Hill, T. Havel, and C. Livermore, "Modeling mechanical energy storage in springs based on carbon nanotubes," Nanotechnology, vol. 20, no. 25, p. 255704, 2009.

[25] V. Krishna, "Spring type analysis for a RBLA device," Stander Symposium Poster Session, 2014.

[26] M. Dassen, "Modelling and control of automotive clutch systems," Report, Tech. Rep., 2003.

[27] A. Rousseau, N. Shidore, R. Carlson, and V. Freyermuth, "Research on phev battery requirements and evaluation of early prototypes," in 7th Advanced Automotive Battery Conference, 2007, pp. 16-18. 
[28] K. B. Wipke and M. R. Cuddy, "Using an advanced vehicle simulator (ADVISOR) to guide hybrid vehicle propulsion system development," 1996.

[29] "Urban dynamometer drive schedules," Environmental Protection Agency, Code of Federal Regulations Part 1065, 2002.

[30] C. Reynolds and M. Kandlikar, "How hybrid-electric vehicles are different from conventional vehicles: the effect of weight and power on fuel consumption," Environmental Research Letters, vol. 2, no. 1, p. 014003, 2007.

[31] R. Stone, "Fatigue life estimates using goodman diagrams," Retrieved August, vol. 17, p. 2012, 2012 .

[32] F. Garofalo, L. Glielmo, L. Iannelli, and F. Vasca, "Optimal tracking for automotive dry clutch engagement," in Proc. of the 15th IFAC congress, 2002. 